\title{
Free to Fly the Rainbow Flag: The Relation Between Collective Autonomy and Psychological Well-being Amongst LGBTQ+ Individuals
}

Frank J. Kachanoff*1, Fiona Cooligan*2, Julie Caouette2, \& Michael J. A. Wohl2

University of North Carolina at Chapel Hill1

Carleton University2

May 20th, 2020

*Frank Kachanoff and Fiona Cooligan contributed equally to this research and share first authorship.

Authors' note:

This is a preprint of this manuscript, currently in press at Self and Identity. This paper is not the copy of record and may not exactly replicate the authoritative document that will be published in Self and Identity.

Correspondence concerning this article should be addressed to Frank J. Kachanoff, University of North Carolina, Department of Psychology and Neuroscience, University of North Carolina at Chapel Hill, Email: fkach@email.unc.edu

This research was supported by a doctoral scholarship from the Social Sciences and Humanities Research Council of Canada (CGSD 767-2013-1903), a post-doctoral scholarship from the Fonds Québécois de Recherche sur la Société et la Culture (FQRSC 206580), post-doctoral funding from the Ford Motor Company Center for Global Citizenship at Northwestern University, and post-doctoral funding from the Charles Koch Foundation awarded to Kachanoff. This research was also funded by a Social Sciences and Humanities Research Council of Canada grant awarded to Wohl (\#435-2012-1135). Fiona Cooligan is now at the University of Ottawa, Ottawa, Ontario, Canada. 


\begin{abstract}
In three experiments, we tested whether LGBTQ+ individuals experience greater psychological well-being when they feel other groups support (versus restrict) their community's collective autonomy to express its social identity. LGBTQ+ individuals recruited from a Canadian city (Experiment 1a), and nationally from the United States (Experiment 1b), retrospectively recalled feeling more personal autonomous need satisfaction, and in turn, greater psychological wellbeing during a time in their community's history when they felt their collective autonomy was supported (versus restricted). In Experiment 2, US participants reported greater personal autonomous need satisfaction and psychological well-being after reflecting on how their community presently had versus lacked collective autonomy. Effects remained robust controlling for anti-LGBTQ+ discrimination, personal autonomy support, and openness about one's gender/sexuality identity.

Key words: Collective Autonomy; Personal Autonomy; Psychological Needs; Psychological Well-Being; LGBTQ+ Community; Self-Determination Theory; Social Identity Theory
\end{abstract}




\section{Free to Fly the Rainbow Flag: The Relation Between Collective Autonomy and Psychological Well-being Amongst LGBTQ+ Individuals}

Although Lesbian, Gay, Bisexual, Transgender, Queer, and/ or other marginalized sexual/gender communities are colloquially combined into a superordinate LGBTQ+ community, each sub-group is unique and faces its own distinct challenges as a marginalized minority (McLean, 2008). That said, LGBTQ+ individuals sometimes feel a sense of kinship to their LGBTQ+ community as a whole because of the similar experiences of marginalization they all face (Górska \& Bilewicz, 2015; Paterson, Brown, Walters, 2018; Paterson, Brown, Walters, 2019). LGBTQ+ individuals are not directly born into a family or community of other individuals like themselves (as is the case with marginalized racial or ethnic groups). As a result, some LGBTQ+ individuals deliberately form a community by seeking out individuals who have similarly been discriminated against on the basis of their gender identity or sexual orientation (Brown, 2007; Detrie \& Lease, 2007). Thus, LGBTQ+ identity and culture are based on the reality of diversity (e.g., we are the same because we are different; Adler \& Raz, 2009). The kinship amongst different members of the community is consequential: LGBTQ+ individuals are personally affected by instances of hate against community members, regardless of whether they identify as belonging to the same sub-group (or not) (Paterson et al., 2018).

Because LGBTQ+ culture is derived from a collection of diverse groups, it is continuously developed and expressed by community members through collective showings of resistance, designated LGBTQ+ spaces that allow for the safe development and expression of LGBTQ+ identity, and public events such as pride parades (Bauer \& Mahn, 2014; Kitzinger \& Wilkinson, 1994). It is a reality, however, that individuals outside the community sometimes interfere with LGBTQ+ individuals expressing their culture. In the current research, we 
investigated whether members of the LGBTQ+ community, regardless of their sub-group, are personally affected by the perception that their LGBTQ+ community is restricted from openly expressing its sexual or gender identity.

Bans on lesbian, gay, or bisexual (LGB) individuals' freedom to marry, or policies explicitly telling LGB individuals not to disclose their sexual identity (e.g., the US military policy to not-disclose a non-heteronormative sexual orientation; Burrelli \& Feder, 2009) send a message to LGB individuals that their group should suppress its sexual identity. Similarly, public debates about whether Trans individuals should be able to use washrooms of their choice (DeStefano, 2019; Levin, 2019), have access to hormone therapy (Callaghan, 2007; Kitzinger \& Wilkinson, 1994), or be able to serve in the military (Delgardo, 2019), signal to transgender and genderqueer individuals that their group must suppress expressing core aspects of its identity. Psychologically, such restrictive policies undermine LGBTQ+ individuals' collective autonomy: The perception that their LGBTQ+ community (or their own subgroup within the community) can freely express its own social identity and ways of behaving openly in society without being unduly restricted by other groups (Kachanoff, Kteily, Khullar, Park, \& Taylor, in press; Kachanoff, Taylor, Caouette, Khullar, \& Wohl, 2019; Kachanoff, Wohl, Koestner, \& Taylor, 2020; Parker, Ryan, Duineveld, \& Bradshaw, 2019).

Building on the work of others (Brown, 2007; Mulé, 2006; Ryan, Hunger, \& Major, 2017), we propose that experiencing collective autonomy restriction is associated with significant well-being challenges often faced by LGBTQ+ individuals (e.g., increased anxiety and depression, and reduced life-satisfaction; see Burton, Marshal, Chisolm, Sucato, \& Friedman, 2013; Guidotto, 2005; King et al., 2008; Semlyen, King, Varney, \& Hagger-Johnson, 2016). While previous research has documented the consequences of collective autonomy for 
psychological well-being in the context of race, ethnicity, nationality, or religion (e.g., Kachanoff et al., 2019), the present research is the first to consider the consequences of collective autonomy for well-being with respect to one's gender and/or sexual identity, and, with respect to a marginalized minority group identity. This extension is important given that marginalized sexual minority groups and genderqueer individuals are underrepresented in the psychological literature, often experience diminished psychological well-being relative to heterosexual and gender-conforming individuals, and are especially at risk of experiencing collective autonomy restriction given their vulnerable position in society.

\section{Personal Autonomy Support and the LGBTQ+ Community}

Self-determination theory (SDT; Ryan \& Deci, 2017) proposes that people have a basic psychological need to feel personally autonomous: individuals want to articulate and freely express all aspects of the person they see themselves to be (i.e., their self-concept; Weinstein, Przybylski, \& Ryan, 2012). This contention has been substantiated by a wealth of research showing that satisfying one's need for personal autonomy is robustly positively associated with psychological well-being across different cultures and social contexts (Chen, Van Assche, Vansteenkiste, Soenens, \& Beyers, 2015; Chirkov, Ryan, Kim, \& Kaplan, 2003; Deci, Olafsen, \& Ryan, 2017; Van Petegem, Soens, Vansteenkiste, \& Beyers, 2015).

Individuals satisfy their psychological need for personal autonomy when others (e.g., parents, teachers, friends, coworkers) unconditionally accept them regardless of how they define and express who they are. This type of support has been termed personal autonomy support. Unfortunately, people are sometimes controlled and pressured by others to think and behave in ways that are discordant with who they truly want to be; Roth, Assor, Niemiec, Ryan, \& Deci, 2009). In personally controlling (versus personally autonomy supportive) environments, a 
person's basic psychological need for autonomy is thwarted, and psychological well-being is undermined.

Given that LGBTQ+ identities are marginalized and rejected in society, LGBTQ+ individuals often feel that their personal freedom to express their sexual or gender identity is being controlled or restricted by others (D’Augelli, 2002, Goh, Kort, Thurston, Benson, \& Kaiser, 2019; Herek, 2009; Ryan, Legate, \& Weinstein, 2015). However, this is not always the case: LGBTQ+ individuals can also experience autonomy supportive interpersonal relationships. In such relationships, LGBTQ+ individuals feel they are accepted and thus free to express their sexual or gender identity unconditionally (Legate, Ryan, \& Rogge, 2017; Legate, Ryan, \& Weinstein, 2012; Ryan, Legate, Weinstein, \& Rahman, 2017; Weinstein, Ryan, et al., 2012). For example, when Lesbian, Gay or Bisexual individuals feel their personal autonomy is supported, they are more open to coming "out" about their sexual identity, and experience an associated increase in personal autonomous need-satisfaction and psychological well-being (Pachankis, 2007; Quinn \& Earnshaw, 2011; Legate et al, 2012; 2017; Ryan et al., 2017).

\section{Collective Autonomy Support and the LGBTQ+ Community}

We contend that independent of whether LGBTQ+ individuals feel personally autonomy supported or restricted to express their gender or sexual identity within interpersonal contexts, LGBTQ+ individuals also have a coexisting perception of whether their community's collective autonomy is supported or restricted within intergroup contexts. For example, a trans individual may feel that their own doctor personally supports them unconditionally to express their gender identity (even if it differs from their sex at birth). At the same time, however, they may feel that the trans community faces societal-level pressures to conform to heteronormative stereotypes 
and that doctors generally condemn members of their community undergoing hormone replacement therapy (i.e., collective autonomy restriction).

Necessarily, personal autonomy support and collective autonomy are related conceptually. However, we argue that they are distinct. This is because individuals often have discrepant perceptions of how they are personally treated on the basis of their group membership, and how their group collectively is treated in society (Taylor, Wright, Moghaddam, \& Lalonde, 1990). Past work has shown that a person may feel their group experiences discrimination even though they believe they have not personally experienced discrimination (Taylor et al., 1990). Relatedly, Ryan, Hunger and Major (2017) have distinguished between systemic structural stressors that influence the LGBTQ+ community collectively and interpersonal stressors that are personally experienced by individual community members.

Herein, we extend this prior work by considering the relation between autonomy at the personal and collective level, beyond the more general distinction between personally and collectively experienced discrimination focused upon in previous research (Ryan, Hunger et al., 2017; Taylor et al., 1990). We hypothesize that LGBTQ+ individuals' perception that their LGBTQ+ community (as a whole) has autonomy to express its gender or sexual identity has important implications for an LGBTQ+ individual's personal autonomous need-satisfaction and psychological well-being (independent of whether LGBTQ+ members feel that they are provided with personal autonomy support in their interpersonal relationships). Because people derive part of their sense of self (i.e., a social identity) from the social groups to which they belong, and often desire to express aspects of particular social identities that are deemed import to one's selfconcept (Oyserman, 2007; Tajfel \& Turner, 1979), their personal sense of autonomy should be intimately tied to whether they feel that their group can openly express its social identity. 
The idea that collective autonomy restriction is distinguishable from general discrimination is consistent with previous research. Collective autonomy restriction is likely positively associated with feeling that one's group is discriminated against because collective autonomy restrictions can be a signal of broader systemic discrimination. However, groups may impose its values on another group in an ostensibly benevolent fashion (Bruneau, Szekeres, Kteily, Tropp, \& Kende, 2019). Some healthcare practitioners, for example, have defended forcefully changing the sexual orientation of LGB individuals (Nicolosi, 1991), or preventing transgender or genderqueer individuals from accessing hormone therapy (Callaghan, 2007; Kitzinger \& Wilkinson, 1994), on the basis that such restrictions are beneficial to LGBTQ+ individuals' well-being (despite evidence to the contrary). Groups can also be intolerant of specific customs or practices of another group, and at the same time, hold neutral or even positive attitudes towards the group. On the other hand, groups can signal prejudiced attitudes towards another group without forcefully trying to prevent that group from defining and expressing its identity (Verkuyten \& Yogeeswaran, 2017). Given these distinctions, we predicted that experiencing collective autonomy restriction should uniquely relate to reduced personal autonomous need satisfaction and psychological well-being when accounting for LGBTQ+ individuals' general perceptions of anti-LGBTQ+ discrimination.

\section{The Moderating Role of Group Identification}

It is possible that some members of the LGBTQ+ community may be more personally affected by the collective autonomy of their group than others. For instance, the extent to which group psychological well-being is associated with experiences of discrimination is conditional on how strongly identified people are with their ingroup (e.g., Bockting, Miner, Romine, Hamilton, \& Coleman, 2013; McLemore, 2018). On this basis, we tested whether the relation between 
collective autonomy restriction and personal autonomy and well-being is similarly conditional on group identification.

On the basis of previous research in the context of anti-group discrimination, it is unclear whether group identification might protect against or exacerbate the negative psychological consequences of collective autonomy restriction. Deriving a sense of belonging from other group members (i.e., ingroup ties) and feeling positive emotions towards one's group (i.e., positive ingroup affect) has been shown to buffer members of stigmatized ethnic minorities (Branscombe, Schmitt, \& Harvey, 1999; Schmitt, Branscombe, Postmes, \& Garcia, 2014) and genderqueer individuals (Bockting, et al., 2013) against the negative well-being consequences associated with experiencing discrimination. Thus, it is possible that group members who strongly identify with their group (i.e., high identifiers) may be similarly protected from the undermining effects of collective autonomy restriction because their personal sense of autonomy is fortified from internalizing a strong and positive bond with their social group (Amiot \& Sansfaçon, 2011; Amiot \& Aubin, 2013; Greenaway, Amiot, Louis, \& Bentley, 2017).

However, high identifiers have also been shown to be more reactive to the perceived injustices inflicted on their group, which influences them to personally engage in collective action initiatives to help their ingroup (Giguère \& Lalonde, 2011; Van Zomeren, Postmes, \& Spears, 2008; Van Zomeren, Spears, \& Leach, 2008). Moreover, experiencing group-based discrimination has been shown to have especially negative well-being consequences for people who see their gender identity as central to their overall sense of self (i.e., ingroup centrality; McLemore, 2018). Thus, individuals who are highly identified with their LGBTQ+ community may be more likely experience constraints imposed on their community as personal constraints. In the present research, we explored these alternative hypotheses by assessing whether different 
social identity factors (ingroup ties, ingroup affect, and centrality; see Cameron, 2004;

Kachanoff, Ysseldyk, Taylor, de la Sablonnière, \& Crush, 2016 for reviews) moderate the relation between collective autonomy restriction and personal autonomy, and thus, the downstream effect on psychological well-being.

\section{Overview of Present Research}

We tested our hypotheses with three independent samples of self-identified LGBTQ+ individuals. In Experiment 1 a and Experiment $1 \mathrm{~b}$ we examined whether LGBTQ+ individuals would retrospectively recall feeling greater personal autonomous need satisfaction and psychological well-being during a time in which they felt their LGBTQ+ community had its collective autonomy supported (versus restricted). In Experiment 2 we examined whether we could influence people's state levels of personal autonomous need satisfaction and psychological well-being by having them describe a way in which they presently felt that their LGBTQ+ community enjoyed collective autonomy support (versus restriction).

Because all of the different sub-communities within the LGBTQ+ community have historically faced restrictions to their collective autonomy (e.g., Burrelli \& Feder, 2009; Callaghan, 2007; Delgardo, 2019; DeStefano, 2019; Kitzinger \& Wilkinson, 1994; Levin, 2019), access to our studies was open to individuals from all sub-groups within the LGBTQ+ community. Our decision to focus on LGBTQ+ individuals' perception of their superordinate LGBTQ+ identity is consistent with past research with LGBTQ+ individuals (e.g., Paterson, et al., 2018, 2019), and past work with other marginalized groups such as indigenous communities (e.g., see Neufeld and Schmitt (2019) for a discussion of how distinct Indigenous groups in 
North America have formed a meaningful superordinate Indigenous identity through their shared colonial history)1.

We also tested whether the effects of our manipulations were robust when accounting for a) personal autonomy support from close others (all Experiments), b) general discrimination against the LGBTQ+ community (Experiment 1a and Experiment 2), and c) the extent to which individuals feel they can personally express their gender or sexual identity openly (Experiment $1 \mathrm{~b}$ and Experiment 2). In Experiment $1 \mathrm{~b}$ and Experiment 2, we also explored whether LGBTQ+ individuals reported feeling more open about their gender/sexual identity when asked to describe how their community has (versus lacks) collective autonomy. In the same way that LGBTQ+ individuals may be more open about their identity within personally autonomy-supportive contexts (e.g., Legate et al, 2012; 2017), individuals may also feel they can be more open across contexts when they perceive their community to be supported in broader society.

Given the LGBTQ+ community is an under-represented group within the university and local urban communities in which Experiment 1a was conducted, statistical power considerations were based on our ability to recruit as many participants as possible during the academic year. For Experiment 1b, we recruited more broadly from the American LGBTQ+ community via Qualtrics Panel Service. As such, sample size was based on an a priori power analysis, which revealed that a sample of 375 individuals was required to obtain statistical power of .80 (assuming a Cohen's $f$ of .18 based on the effect sizes reported by Kachanoff and colleagues, 2019). Because greater statistical power is required to detect an interaction between two

\footnotetext{
1 Our results were largely consistent when examining the effects of condition only amongst individuals who identified as Lesbian, Gay, Bisexual or Queer, versus individuals who identified as Trans or Genderqueer (See Supplemental Table 1a and 1b). Our results were also robust when controlling for whether individuals were LGBQ versus Trans or Genderqueer, and the condition by community-sub-membership interaction (See Supplemental Table $2 \mathrm{a}$ and $2 \mathrm{~b}$ ).
} 
variables, we explored the question of whether group identification moderates the relation between collective autonomy support (versus restriction) and personal autonomy/psychological well-being by merging the samples from Experiment 1a and 1b. In Experiment 2 we recruited a larger sample of 400 individuals to increase our statistical power for probing moderation. Experiment $1 \mathrm{~b}$ (https://aspredicted.org/blind2.php) and Experiment 2 (http://aspredicted.org/blind.php? $\mathrm{x}=43$ gi8n) were pre-registered on AsPredicted.org. All materials and data from all three experiments are available via the Open Science Framework (OSF): https://osf.io/n3kfh/?view_only=153f0d491f534bb1bd1a52cbd120ea47.

\section{Experiment 1a and 1b: Retrospective Personal Autonomous Need Satisfaction and}

\section{Psychological Well-Being}

In Experiment 1a and 1b, we asked LGBTQ+ individuals to retrospectively reflect on and write about a time in which they felt that their LGBTQ+ community had or lacked collective autonomy. We hypothesized that LGBTQ+ individuals would retrospectively recall feeling greater personal autonomous need satisfaction and psychological well-being during a time in which their LGBTQ+ community experienced collective autonomy support (versus restriction).

\section{Experiment 1a}

\section{Participants}

LGBTQ+ individuals from a large Canadian urban city were recruited between 2016 to 2017 via: (1) a local university-based Gender and Sexuality Resource Centre, (2) a local university campus, and (3) broader LGBTQ+ networks by word of mouth from LGBTQ+ community members. Data was collected via online survey to maximize privacy. The survey was accessed by 188 participants who identified as being part of the LGBTQ+ community. 
Ultimately, 114 participants $\left(M_{\mathrm{age}}=21.66, S D=4.80\right)$ passed four attention checks and completed the survey2.

To signal to participants that we understood that there are distinct groups within the larger LGBTQ+ community, we first asked participants to indicate which sub-group(s) within the broader LGBTQ+ umbrella they personally identified with (participants could select multiple sub-groups). These groups were: The trans community (22.8\%), the Gay and Lesbian community (61.4\%), the LGBTQ+ community as a whole (57\%), another sub-group not listed (8.8\%), and/or as non-heterosexual and or non-cisgender, but not connected with any "community" based on gender or sexual identity $(13.20 \%) 3$. We also asked participants whether or not they identified as an ethnic or cultural minority. A total of $24.6 \%$ responded "yes". We permitted those who reported "yes" to describe their ethnic minority identity. We re-coded these responses according to the guidelines of the Canadian census. Results were as follows: Asian/South Asian/ South East Asian (21.4 \%), Black/African/ Caribbean (17.9\%), Arab (17.9\%), Metis/First Nations/Inuit (14.3\%), Latin American (10.7\%) and Other/Mixed Race (17.9\%).

\section{Procedure}

Participants were randomly assigned to the collective autonomy support or restriction writing conditions. Corresponding to their condition, participants were either asked to write

2 The percentage of participants who viewed the writing task but did not pass the inclusion criteria did not differ significantly between the collective autonomy restriction condition $(25.7 \%$; $19 / 74$ of participants $)$ and the collective autonomy support condition $\left(23.4 \% ; 18 / 77\right.$ participants), $\chi_{2}=0.07, p=.80$. Our findings remain consistent when including all participants (see open data and syntax). Our results also remained consistent when using more stringent exclusion criteria such that we excluded people who: wrote that they could not think of, or articulate a response; wrote about the opposite type of experience as what was asked (i.e., they gave an example of collective autonomy support if in the restriction condition, or an example of restriction in support) or wrote about topics that were related to their community but not collective autonomy restriction (See Supplemental Table 3).

3 The patterns of significance for the effects of experimental condition on collective autonomy restriction, personal autonomous need satisfaction, and psychological well-being was consistent for individuals who did and did not indicate that they identified with the superordinate LGBTQ+ community identity as a whole. See Supplemental Table 4. 
about a time when they felt that their LGBTQ+ community had collective autonomy or lacked collective autonomy (adapted from Kachanoff et al., 2019; See Supplemental Materials for complete instructions).

In all conditions, participants were first provided with a general description of what collective autonomy involves within the context of their LGBTQ+ community. Specifically, participants read:

"Collective autonomy refers to your subjective perception that your group - in this case your LGBTQ+ community - can determine its own group identity and act in accordance with its group identity. In other words, collective autonomy means that you, as a people, have determined what makes you who you are as a group, and that you and your community feel free and welcome in society to act in ways that reflect your group identity. Several different social contexts (actions of other groups, attitudes of mainstream society, political and legal decisions, etc.,) might lead you and your group to feel either a lack of collective autonomy OR a strong sense of collective autonomy [...] We want to know about a time you can recall when you felt that your community had/ did not have collective autonomy in one way or another."

Following this general description, participants in the collective autonomy support condition read the following:

"You may perceive a strong sense of collective autonomy when your group benefits from open societal processes that allow your group to freely define who you are as a people, or processes that support your group's right to your own customs and values and respect your right to act in ways that reflect who you are as a people. For example: you might think of a specific event that you feel had a supportive impact on the LGBTQ+ 
community (e.g., marriage equality laws passed in U.S., more exposure for trans people in media - tv shows, tours, etc.,)."

In contrast, participants in the collective autonomy restriction condition read the following:

"You may perceive a lack of collective autonomy when your group is affected by controlling societal processes that prevent your group from freely defining who you are as a people, or processes that impose customs or values on your group, or restrict you from acting in ways that reflect who you are as a people. For example: you might think about an event that you feel had a threatening impact on the $L G B T Q+$ community (e.g., prohibition of $L G B T Q+$ people/messages in Russia, lack of support for gender neutral spaces - washrooms, children's clothes/toy sections, etc.,)."

There was no specific time or word requirements from participants for the writing task. Following the writing task, participants completed a questionnaire assessing the outcomes of interest in present research. Participants were then debriefed and compensated for their time.

\section{Measured Variables.}

All measures were anchored at 1 (Strongly Disagree) and 7 (Strongly Agree).

Collective Autonomy Restriction. Participants rated how much they felt that other groups tried to restrict their collective autonomy during the time they described using eight items adapted from Kachanoff and colleagues (2019). Example items are: "My LGBTQ+ community did NOT feel free to express our identities and practice our traditions openly in society" and "My LGBTQ+ community felt free to determine who we are as a people" (reverse scored; $\alpha=.87$ ).

Personal Autonomous Need Satisfaction. Participants rated how personally autonomous they felt during the time they described using six items adapted from Sheldon and Gunz' (2009) 
psychological needs satisfaction scale. Sample items are: "My choices expressed my 'true self'" and "there were people telling me what I had to do" (reverse scored; $\alpha=.81$ ).

Psychological Well-Being (Life Satisfaction). Participants rated their level of psychological well-being during the time they described using six items adapted from Diener's (1985) satisfaction with life scale. Sample items are: "In most ways my life was close to my ideal" and "I was satisfied with my life" (reverse scored; $\alpha=.82$ ).

Perceived Discrimination. We assessed participants' general perceptions of discrimination against the LGBTQ+ community during the event/time they described using three items taken from Kachanoff and colleagues (2019). Sample items are: "My community was the target of prejudice" and "It was rare that members of my community faced discrimination" (reverse scored; $\alpha=.83$ ).

Personal Autonomy Support. We assessed the extent to which participants felt they had autonomy-supportive relationships with two parental figures (Weinstein et al., 2012). We asked participants to "identify people that best represent parental figures - someone who has had a significant role in raising or caring for you". Participants rated three items relating to when they are with each parental figure: "I feel free to be who I am", "I have a say in what happens and can voice my opinion" and "I feel controlled and pressured to be certain ways" (reverse scored; $\alpha$ Figure1 $=.84, \alpha$ Figure2 $=.80)$. We computed the average score of participants' ratings to the two figures $(r=.07, p=.44)$.

Group Identification. We assessed three relevant sub-dimensions of group identification with six items which we adapted from Cameron (2004). Two items assessed whether people felt close and connected to the other members of their LGBT+ community (i.e., ingroup ties, $r(114)=.586, p<.001)$ : "I feel strong ties to other LGBTQ+ community members" ; "I don't feel a 
sense of being "connected" with other members of the LGBTQ+ community" (reverse coded).

Two items assessed whether people felt that their LGBT+ identity is a central part of their selfconcept (i.e., ingroup identity centrality; $r(114)=.480, p<.001)$ : "In general, being LGBTQ+ is an important part of my self-image"; "Overall, being LGBTQ+ has very little to do with how I feel about myself' (reverse coded). Two items assessed whether people felt positive versus negative affect towards their LGBTQ+ community membership (i.e., ingroup affect; $r(114)=.623$, $p<.001)$ : "In general, I am glad to be LGBTQ+" and "I don't feel good about being LGBTQ+" (reverse coded).

\section{Results}

Descriptive statistics, including inter-scale correlations and grand means, are summarized in Table 1.

Writing Check and Potentially Overlapping Variables. As expected, there was a between condition difference in participants' recollections of collective autonomy restriction: participants reported having felt less collective autonomy restriction in the collective autonomy support condition $(M=4.22, S D=1.24)$ compared to the collective autonomy restriction condition $(M=5.01, S D=1.15), F(1,112)=12.19, p<.001, \eta_{2}=.10$. Perceived discrimination against the LGBTQ+ community was also marginally lower in the collective autonomy support condition $(M=5.02, S D=1.63)$ versus collective autonomy restriction condition $(M=5.54, S D=1.15$, $F(1,107)=3.63, p=.060, \eta_{2}=.03$. Perceptions of personal autonomy support did not differ significantly by condition, $F(1,105)=1.11, p=.295, \eta_{2}=.014$ (See Table 2$)$.

4 We also measured the extent to which participants perceived personal autonomy support from other members of their LGBTQ+ community (see supplemental materials). As expected, there was not a between condition difference in recollections of receiving personal autonomy support from other community members, $F(1,114)=.37, p=.56$, $\eta_{2}=.003$, and the effects of condition on personal autonomy and psychological well-being remained consistent controlling for this factor. 
Personal Autonomous Need Satisfaction. Participants reported feeling significantly more personal autonomous need satisfaction during a time in which they felt that their LGBTQ+ community enjoyed collective autonomy $(M=4.66, S D=1.27)$ versus lacked collective autonomy $(M=3.81, S D=1.19), F(1,112)=13.62, p<.001, \eta_{2}=.11$. This effect remained robust when controlling for perceived discrimination, and personal autonomy support, $F(1,103)=11.84$, $p<.001, \eta_{2}=.10$.

Psychological Well-Being. Psychological well-being did not differ between the collective autonomy supportive $(M=4.18, S D=1.24)$ and collective autonomy restrictive conditions $(M=4.09, S D=1.41), F(1,112)=.15, p=.70, \eta_{2}=.001$. However, a simple-mediation analysis using PROCESS V3.2 (Hayes, 2017, Model 4, 5,000 boot-strapping confidence intervals) revealed that writing about a time or event in which one's LGBTQ+ community enjoyed (versus lacked) collective autonomy was indirectly associated with retrospective psychological well-being through greater recollections of personal autonomous need satisfaction (indirect effect $=.33, S E=.11,95 \% \mathrm{CI}[.13, .56]) 5$. The indirect effect of condition on psychological well-being through personal autonomous need satisfaction remained significant when repeating the analysis controlling for general discrimination and personal autonomy support (indirect effect $=.21, S E=.09,95 \% \mathrm{CI}[.06, .39])$.

We also tested a multiple-mediation model. We included the possible indirect effects of condition on psychological well-being through personal autonomy support, discrimination, as well as, personal autonomous need satisfaction (in parallel). The indirect path through personal

5 We tested a reverse pathway in which writing task condition impacted personal autonomy through changes in psychological well-being. We found that the indirect effect of condition on personal autonomy through well-being is non-significant: Indirect effect $=.03,95 \% \mathrm{CI}[-.13, .21]$. The direct effect of condition on personal autonomy was significant in the model, $b=.82,95 \% \mathrm{C} 1[.39,1.25], p<.01$. 
autonomous need satisfaction $(.28,95 \%$ BSCI $[.05, .43])$ was significant, while the indirect path through personal autonomy support (-.06, 95\% BSCI [-.20, .07]) was non-significant. We observed a trending indirect effect of condition on well-being through discrimination $(.12,95 \%$ BSCI $[-.00, .30])$.

\section{Experiment 1b}

The procedure of Experiment $1 \mathrm{~b}$ was almost identical to Experiment 1a except that we included additional measures of psychological well-being that assessed depressive symptoms, anxious emotions, anger, and self-esteem to be more consist with previous work by Legate and colleagues (2017). We also broadened our assessment of personal autonomy support to include four important interpersonal contexts (parents, friends, peers at school, and colleagues at work). Lastly, we assessed the extent to which LGBTQ+ individuals felt that they could be open about their sexual/gender identity in each of these interpersonal contexts (Legate et al., 2012, 2017).

\section{Method}

\section{Participants}

We commissioned Qualtrics Panels in January 2019 to recruit 400 self-identified LGBTQ+ individuals living in the United States6. In total, 506 participants who self-identified as being a US citizen and part of the LGBTQ+ community accessed and completed the survey distributed by Qualtrics. However, 134 participants failed to pass two attention checks imbedded in the survey and were thus excluded7. We excluded two additional participants who typed in random letter strings into the writing task. Our final sample consisted of 370 participants

6 We over sampled because we expected some participants might fail our attention checks (see pre-registration). 7 The percentage of participants who viewed the writing task but did not pass the inclusion criteria did not differ significantly between the collective autonomy restriction condition (36\%; 63/175 of participants) and the collective autonomy support condition ( $36 \%$; $71 / 195$ participants), $\chi_{2}=0.001, p=.93$. Our findings remain consistent when including all participants (see open data and syntax). Consistent with Experiment 1a, we also report results using stricter exclusion criteria based on participants written responses. The pattern of significance for all outcomes was identical (see Supplemental Table 3). 
(Mage=33.68, $S D=13.40)$. Participants selected whether they felt strongly connected to the following sub-groups of the LGBTQ+ community (participants could select multiple groups): The trans community (13.2\% selected), the Gay and Lesbian community ( $55.7 \%$ selected), the LGBTQ+ community as a whole (50\% selected), another community not listed (4.9\% selected), and/or as non-heterosexual and or non-cisgender, but not connected with any "community" based on gender or sexual identity $(13.20 \%) 8$.

With respect to gender demographics, $70.3 \%$ of the sample preferred the gender pronoun "she/her/feminine, $23.8 \%$ preferred "he/him/masculine", and $5.7 \%$ preferred "they/them/neutral". With respect to the ethnic composition, $71.9 \%$ of the sample identified as White/Caucasian, 11.4\% identified Black/African American, 8.1\% identified as Latino/Hispanic, 5.1\% identified as biracial/mixed race, $2.2 \%$ identified as Asian/Asian American/Pacific Islander, $1.1 \%$ as Native American, and .3\% identified as "other".

\section{Procedure}

Akin to Experiment 1a, participants were randomly assigned to write about a time when they felt that their LGBTQ+ community had or lacked collective autonomy. The writing prime was the same as that which we used in Experiment 1a, with the exception we refined the prime to be more succinct (i.e., repetition was removed and the sentence structure edited for readability).

In all conditions participants first read a general description of collective autonomy. Specifically, they read, "Collective autonomy refers to whether you feel that your group - in this case your LGBTQ+ community -is free to define and express who you are as a people (e.g., your values and beliefs, your ways of behaving)".

Participants in the collective autonomy support condition then read:

8 The effect of condition on all outcomes was significant for individuals who did and did not identify on the basis of the superordinate LGBTQ+ identity (See Supplemental Table 4). 
"You may perceive a strong sense of collective autonomy when you feel that other groups in society support your group's freedom to express your own customs and values and to act in ways that reflect who you are as a people. Please think about your own experiences as part of the $L G B T Q+$ community. We want to know about a time you can recall when you felt that your community's collective autonomy was supported. For example: There may have been a specific time or event that made you feel that the $L G B T Q+$ community had the support of groups from outside the community (e.g., marriage equality laws passed in the U.S., more awareness and exposure for trans people in the media - tv shows, tours, etc.,)."

In contrast, participants in the collective autonomy restriction condition read:

"You may perceive a lack of collective autonomy when you feel that other groups in society try to control how your group expresses your own customs and values and restricts your group from acting in ways that reflect who you are as a people.

Please think about your own experiences as part of the LGBTQ+ community. We want to know about a time you can recall when you felt that your community's collective autonomy was threatened. For example: There may have been a specific time or event that made you feel that the LGBTQ+ community was being restricted by groups from outside the community (e.g., prohibition of $L G B T Q+$ people and messages in Russia, lack of support for making things more gender neutral - washrooms, children's clothes and toy sections in stores, etc.,)'”.

Following the writing task, participants completed a questionnaire battery assessing our outcomes of interest, and were debriefed and compensated for their time.

\section{Measured Variables.}


All measures were anchored at 1 (Strongly Disagree) and 7 (Strongly Agree).

Collective autonomy restriction $(\alpha=.82)$ and personal autonomous need satisfaction $(\alpha=.81)$ were assessed with the same items used in Experiment 1a. Psychological well-being was assessed as a composite of: Life-satisfaction (3 items; Diener, et al., 1985; $\alpha=.82$ ); Self-esteem (3 items; Rosenberg, 1965; $\alpha=.78$ ); Depression (3 items; Radloff, 1977, CES-D scale; $\alpha=.88$ ), Anxiety (3 items; Goldberg \& Hillier, General Health Questionnaire, 1979; $\alpha=.90)$, and Anger (3 items; Spielberger, Jacobs, Russell, \& Crane, 1983, state-trait scale; $\alpha=.89$ ). Consistent with Legate and colleagues $(2012,2017)$, we formed a composite well-being score by taking the mean of all items $(\alpha=.95)$. Importantly, we found an identical pattern of results for each separate wellbeing measure (Supplemental Table 5).

We assessed the extent to which people felt that they could be open about their sexual/gender identity in four social contexts (with family, friends, peers at school, colleagues at work) using one item adapted from Legate and colleagues (2017): "I felt open and comfortable about my sexual and/or gender identity around [my family/my friend/my peers at school/my colleagues at work]". We created an overall openness score by taking the mean of people's responses across the four contexts $(\alpha=.83)$. Lastly, we assessed whether participants felt their personal autonomy was supported with family, with friends, with peers at school, and with colleagues at work. For each context participants responded to 3 items (adapted from Legate et al., 2017). A sample item is: "I felt that my [parents/friends/peers at school/colleagues at work] provided me with choices and options during our interactions". We then formed an aggregate score by taking the mean of personal autonomy support felt across all four conditions $(\alpha=.91)$. 
Lastly, to examine group identification, ingroup ties $(r(369)=.62, p<.001)$, ingroup identity centrality $(r(368)=.=.33, p<.001)$, and ingroup affect $(r(368)=.=.42, p<.001)$ was assessed using the same 2-item pairs described in Experiment 1a9.

\section{Results}

Descriptive statistics including inter-scale correlations and grand means are summarized in Table 3.

\section{Writing Check and Potentially Overlapping Variables. LGBTQ+ community}

members recounted experiencing less collective autonomy restriction when they were asked to describe a time in which their LGBTQ+ community experienced collective autonomy support $(M=3.76, S D=1.31)$ compared to when they were asked to describe collective autonomy restriction $(M=4.39 ; S D=1.23), F(1,367)=22.29, p<.001, \eta_{2}=.06$. Participants in the collective autonomy support condition $(M=4.52, S D=1.47)$ versus collective autonomy restriction condition $(M=4.23, S D=1.42)$ reported having received marginally greater personal autonomy support within their interpersonal interactions (i.e., aggregating across all four contexts), $F(1,366)=2.83$, $p=.093, \eta_{2}=.008$. When examining the effect of condition for each specific context, we observed that this marginal trend was driven by differences in autonomy support within school and work contexts more so than parental or friendship contexts (See Table 4).

Openness about Sexual or Gender Identity. When computing an aggregate (mean) score of openness collapsing across the four different contexts, participants in the collective autonomy support condition recalled being more open about their sexual identity $(M=4.50$,

9 We note that while the item strings assessing group identification were identical in both Experiments (i.e., they were phrased with respect to the LGBTQ+ community), there were slight differences to the instructions proceeding the item strings. In Experiment 1a, participants were asked to fill the questions with respect to their own specific way of identifying with their LGBTQ+ community (e.g., to the Trans part of the community), while in Experiment $1 \mathrm{~b}$ participants were asked in the instructions to report their membership to their LGBTQ+ community as a whole. 
$S D=1.75)$ than those in the collective autonomy restriction condition $(M=4.13, S D=1.85)$,

$F(1,368)=3.89, p=.049, \eta_{2}=.01$. However, this effect became non-significant when controlling for aggregated perceived autonomy support across the four specific contexts, $F(1,365)=.92$, $p=.34, \eta_{2}=.003$. When examining the effect of condition for each specific context, the condition effect was significant for the school context, marginal for the work context, and non-significant for the friend and parental contexts (See Table 4).

Personal Autonomous Need Satisfaction. Participants recalled feeling significantly more personal autonomous need satisfaction when asked to remember a time in which their LGBTQ+ community enjoyed collective autonomy $(M=5.39, S D=1.30)$ versus lacked collective autonomy $(M=4.50, S D=1.36) ; F(1,368)=40.89, p<.001, \eta_{2}=.10$. This effect was robust when controlling for personal autonomy support and the extent to which LGBTQ+ individuals felt that they could be open about their gender/sexual identity in their inter-personal social contexts (i.e., we entered the aggregate score of (a) personal autonomy support and (b) openness across the four interpersonal contexts as controls); $F(1,365)=36.57, p<.001, \eta^{2}=.09$.

Psychological Well-Being. Participants recalled experiencing significantly greater psychological well-being when asked to recall a time in which their group enjoyed collective autonomy $(M=5.21, S D=1.36)$ compared to when they were asked to recall a time when their group lacked collective autonomy $(M=3.69 ; S D=1.43), F(1,368)=110.11, p<.001, \eta 2=.23$. This effect remained robust when controlling for personal autonomy support and openness about one's sexuality or gender identity, $F(1,364)=106.62, p<.001, \eta_{2}=.23$.

When testing for mediation, we found that recalling a time when the ingroup enjoyed (versus lacked) collective autonomy was indirectly associated with greater recollections of psychological well-being through greater personal autonomous need satisfaction, indirect effect 
$=.59, S E=.10,95 \%$ BSCI $[.41, .78]$. The direct effect of condition on psychological well-being was also significant, $b=.93, S E=.12, p<.001,95 \%$ CI $[.70,1.16] 10$. The indirect effect remained robust when controlling for personal autonomy support and openness about one's sexuality aggregated across the four interpersonal contexts, indirect effect $=.49, S E=.09,95 \% \mathrm{BSCI}[.32$, .67].

We also tested a multiple-mediation model in which we included the possible indirect effects of condition on psychological well-being through personal autonomy support, openness, as well as personal autonomous need satisfaction (in parallel). The indirect path through personal autonomous need satisfaction $(.56,95 \%$ BSCI $[.37, .75])$ was significant, while the indirect path through personal autonomy support $(.00,95 \%$ BSCI $[-.11, .11])$ was non-significant. We observed a trending indirect effect of condition on well-being through openness about one's gender or sexual identity $(.09,95 \%$ BSCI $[-.003, .18])$.

\section{Moderation by Group Identification: Merged Analysis of Experiment 1a and 1b}

We tested for interaction using the merged data from Experiments $1 \mathrm{a}$ and $1 \mathrm{~b}$ (standardizing all variables before merger). We regressed personal autonomous need satisfaction onto condition, the three group identification components (i.e., ingroup identity centrality, ingroup affect, and ingroup ties), and the three two-way interactions between condition and each of the ingroup identification components 11 . We mean centered all continuous predictor variables and contrast coded condition (i.e., $-.5=$ collective autonomy restriction and $.5=$ collective autonomy support). There was a significant relation between positive ingroup affect and personal through changes in psychological well-being. We found that the indirect effect of condition on personal autonomous need satisfaction through well-being is significant: Indirect Effect $=.93[.73,1.14]$. The direct effect of condition on personal autonomous need satisfaction was non-significant in the model, direct effect $=-.04, t(370)=-.37, p=.71$. 11 Supplemental Table 6 reports the interaction effects for Experiment $1 \mathrm{a}$ and Experiment $1 \mathrm{~b}$ analyzed separately. However, we caution that Experiment 1a when analyzed alone was likely underpowered to test the group identification by condition interaction. 
autonomous need satisfaction, such that individuals who felt more positive emotions towards their group membership experienced greater personal autonomous need satisfaction $(b=.28$, $s e=.05, t(482)=6.05, p<.001,95 \% \mathrm{CI}[.19, .38])$. There was no significant relation between personal autonomous need satisfaction and ingroup member ties $(b=-.02, s e=.05, t(482)=-.43$, $p=.669,95 \% \mathrm{CI}[-.12, .08])$ or ingroup identity centrality $\left(b=-.03, s e^{=} .05, t(482)=-.70, p=.481\right.$, 95\% CI[-.13, .06]). The interaction between condition and ingroup identity centrality, and the interaction between condition and ingroup member ties were both non-significant $($ all $t s<1.00)$. However, there was a significant interaction between condition and ingroup affect $(b=.21$, $s e=.09, t(482)=2.22, p=.027,95 \% \mathrm{CI}[.02, .39])$. Describing a time in which one's collective autonomy was supported versus restricted had a larger positive effect on personal autonomous need satisfaction for people who felt high positive affect $(+1 \mathrm{sd} ; b=.86, s e=13, t(482)=6.86$, $p<.001,95 \% \mathrm{CI}[.61,1.11])$ versus low positive affect $(-1 \mathrm{sd} ; b=.44, s e=.13, t(482)=3.54, p<.001$, 95\% CI[.20, .69]) towards their LGBTQ+ group membership, however, both effects were significant.

We regressed psychological well-being onto the same set of predictors used in our first moderation analysis pertaining to personal autonomous need satisfaction. There was a significant relation between positive ingroup affect and psychological well-being, such that individuals who felt more positive about their group membership experienced greater psychological well-being $(b=.22, s e=.05, t(482)=4.72, p<.001,95 \% \mathrm{CI}[.13, .31])$. There was no significant relation between psychological well-being and ingroup member ties $(b=-.04, s e=.05, t(482)=-.74, p=.460$, $95 \% \mathrm{CI}[-.14, .06])$ or ingroup identity centrality $(b=-.07, s e=.05, t(482)=-1.38, p=.167,95 \% \mathrm{CI}[-$ $.16, .03])$. The interaction between condition and ingroup centrality, and the interaction between condition and ingroup member ties on psychological well-being were both non-significant (all $t s$ 
$<1.00)$. There was a trending interaction between condition and ingroup affect, on psychological well-being $(b=.15, s e=.09, t(482)=1.64, p=.102,95 \% \mathrm{CI}[-.03, .33])$ : Describing a time in which one's collective autonomy was supported versus restricted had a larger positive effect on psychological well-being for people who felt relatively high positive affect $(+1 \mathrm{sd} ; b=.91, s e=.12$, $t(475)=7.30, p<.001,95 \% \mathrm{CI}[.67,1.16])$ versus low positive affect $(-1 \mathrm{sd} ; b=.61, s e=.12$, $t(475)=4.82, p<.001,95 \% \mathrm{CI}[.36, .85])$ towards their LGBTQ+ group membership, however, both effects were significant.

Because we found evidence that ingroup affect moderated the effect of condition on personal autonomy, we also tested whether the indirect effect of condition on psychological wellbeing through personal autonomy was conditional on how positive individuals felt towards their LGBTQ+ community (i.e., Process Model 7; 5,000 boot-strapping samples)12. We included ingroup member ties, ingroup centrality, and their interaction with condition as covariates in the model. The index of moderated mediation was significant (Index $=.11, s e=.05,95 \% \mathrm{CI}[0.01$, .22]), such that the indirect effect of condition through personal autonomy was stronger for people with relatively high positive ingroup affect $(+1 \mathrm{sd}$; indirect effect $=.47,95 \% \mathrm{CI}[.33, .61])$ versus relatively low positive ingroup affect $(-1 \mathrm{sd}$; indirect effect $=.24,95 \% \mathrm{CI}[.11, .38])$, but both effects were significant.

\section{Discussion}

Across 2 independent samples_ - one with Canadians (Experiment 1a) and one with Americans (Experiment 1b)—we found that LGBTQ+ individuals recalled experiencing greater personal autonomous need satisfaction, and as a consequence, greater psychological well-being

12 Within this model we allowed ingroup affect to moderate the relation between condition and personal autonomous need satisfaction, but not personal autonomous need satisfaction and psychological well-being because we had no theoretical reason to expect moderation of this relation. 
during a time in which their community experienced collective autonomy support versus restriction. Importantly, these effects were robust controlling for personal autonomy support within one's interpersonal relationships (Experiment $1 \mathrm{a}$ and $1 \mathrm{~b}$ ), general discrimination against one's LGBTQ+ community (Experiment 1a), and openness about one's sexual or gender identity (Experiment $1 \mathrm{~b}$ ). When analyzing the merged data of Experiment $1 \mathrm{a}$ and $1 \mathrm{~b}$ we found evidence that these effects were especially strong for individuals who felt relatively high (versus low) levels of positive affect towards their LGBTQ+ community. Although notably, all simple effects remained significant for individuals with high and low levels of positive affect towards their group.

In Experiment 1a, participants also tended to recount feeling more discrimination during a time in which their group lacked versus had collective autonomy. Thus, to some extent, LGBTQ+ individuals may experience collective autonomy restriction as an indication that other groups generally dislike and discriminate against their ingroup. Importantly however, we found that the significant pathway of the collective autonomy writing task on retrospective psychological well-being through personal autonomous need satisfaction was robust (i.e., it remained significant even when controlling for discrimination, or, when accounting for the indirect effect of the writing task on psychological well-being through perceived discrimination). Thus, collective autonomy restriction (versus support) appeared to be distinct from general discrimination or dislike (Verkuyten \& Yogeeswaran, 2017).

Collective autonomy also appeared distinct from receiving personal autonomy support within interpersonal contexts (i.e., the effect of condition on personal autonomy support was non-significant in Experiment $1 \mathrm{~b}$ and marginal in Experiment $1 \mathrm{~b})$. 
Lastly, in Experiment 1b, we found some evidence that LGBTQ+ community members recalled feeling more open about their sexual or gender identity across different interpersonal contexts when they were asked to describe a time in which their community had (rather than lacked) collective autonomy. The effect appeared to be strongest within non-intimate social contexts (i.e., with peers at school and colleagues at work), rather than within closer relational contexts (i.e., with parents and friends). Thus, whether or not individuals personally feel open about their sexual/gender identity within more intimate relationships may be contingent on the specific characteristics of those particular relationships. On the other hand, feeling open in less intimate interpersonal contexts, such as with peers and colleagues, may not only reflect whether people feel personally supported within those relationships, but also whether they feel that their community is supported in broader society. The effect of condition on openness within interpersonal contexts also became non-significant when controlling for personal autonomy support within those contexts, which speaks to the particular importance of personal autonomy support for being open about one's gender and sexuality.

\section{Experiment 2: State Personal Autonomous Need Satisfaction and Well-Being}

Experiment $1 \mathrm{a}$ and $1 \mathrm{~b}$ used a retrospective design such that we asked participants to report how much personal autonomous need satisfaction and well-being they recalled experiencing during a time they felt their community had or lacked collective autonomy. Thus, we cannot know for certain whether participants actually felt diminished personal autonomous need satisfaction or psychological well-being at that time, or rather, whether people retrospectively assumed that their personal autonomy and well-being was diminished as a function of lacking collective autonomy (when in fact it was not). To address this concern, we conducted a final experiment in which we asked participants to write about one way in which 
they presently felt their community has/lacks collective autonomy. Immediately after this exercise, we asked participants to report on their state levels of personal autonomous need satisfaction and psychological well-being. We included all of the same measures as we did in Experiment 1b, as well as the measure of discrimination used in Experiment 1a. We also again assessed group identification (Cameron, 2004).

\section{Participants}

We used CloudResearch.org to selectively recruit participants from Amazon Mechanical Turk who indicated in a pre-test on CloudResearch that their sexual orientation as either: Gay, Lesbian, Bisexual or Other. Participants also had to have been born in the United States. Data was collected from February 19, 2020 to February 25th, 2020. In total, 427 participants accessed and completed the survey. Twenty participants failed to pass one attention check imbedded in the survey in which they had to select the number three on a likert scale array. Seven participants asked to have their responses removed from the experiment. Finally, elven participants wrote a gibberish response on the writing task (e.g., copy and pasting a response from the internet, or replying in a nonsensical way "e.g., very nice”) 13. Our final sample consisted of 396 participants $\left(M_{\mathrm{age}}=32.89, S D=10.33\right)$. Participants selected whether they felt strongly connected to the following sub-groups of the LGBTQ+ community (participants could select multiple groups): The trans community (10.6\% selected), the Gay and Lesbian community $(62.60 \%$ selected), the LGBTQ+ community as a whole (59.10\% selected), another community not listed

13 Our protocol for exclusion was pre-registered. The percentage of participants who viewed the writing task but did not pass the inclusion criteria did not differ significantly between the collective autonomy restriction condition (9.38\%; 20/213 of participants) and the collective autonomy support condition $(5.14 \% ; 11 / 214$ participants), $\chi_{2}=2.86, p=.090$. Our findings remain consistent when including all participants (see open data and syntax). Consistent with Experiment 1, we also report results using stricter exclusion criteria based on participants written responses. The pattern of significance for all outcomes was identical (see Supplemental Table 3). 
(3.8\% selected), and/or as non-heterosexual and or non-cisgender, but not connected with any “community" based on gender or sexual identity $(10.6 \%) 14$.

With respect to gender demographics, $64.6 \%$ of the sample preferred the gender pronoun “she/her/feminine, $30.2 \%$ preferred "he/him/masculine", and $4.3 \%$ preferred "they/them/neutral", and 1\% preferred "other". With respect to the ethnic composition, $75.8 \%$ of the sample identified as White/Caucasian, 9.3\% identified Black/African American, 6.8\% identified as Latino/Hispanic, 4\% identified as biracial/mixed race, $2.8 \%$ identified as Asian/Asian American/Pacific Islander, .8\% identified as Native American, . $3 \%$ identified as Middle Eastern, and .3\% identified as "other".

\section{Procedure}

As in Experiment 1b, participants were randomly assigned to write about a way in which they felt their LGBTQ+ community had or lacked collective autonomy. The writing primes were identical to Experiment $1 \mathrm{~b}$ except that rather than asking participants to write about a past event, the prime was written in the present tense and participants wrote about how they presently: “feel that your community's collective autonomy is threatened/supported". In this version of the experiment, we also added a timer on the writing page such that a minimum of 2 minutes had to transpire before participants could proceed - this was to increase the likelihood of participants providing thoughtful and complete responses.

Measured Variables. All measures were anchored at 1 (Strongly Disagree) and 7 (Strongly Agree). All measures began with the prompt: "Please respond to the following questions in light of how you feel presently when thinking about the current situation experienced by your LGBTQ+ community that you just described in the writing task." 
Collective Autonomy Restriction $(\alpha=.87)$, Personal Autonomous Need Satisfaction $(\alpha=.85)$, Life-Satisfaction $(\alpha=.90)$; Self-Esteem $(\alpha=.81)$; Depression $(\alpha=.83)$, Anxiety $(\alpha=.91)$, Anger $(\alpha=.90)$, Openness about Sexual/Gender Identity $(\alpha=.79)$ and Personal Autonomy Support $(\alpha=.91)$ around family, friends, school peers, and work colleagues were all assessed using identical measures to Experiment 1b. As in Experiment 1b, we formed a composite well-being score by taking the mean of the life-satisfaction, self-esteem, depression, anxiety, and anger scales $(\alpha=.93)$. Again, we found an identical pattern of results for each separate well-being measure (Supplemental Table 7). For the openness measure, we formed an overall openness score by taking the mean of people's responses across the four contexts $(\alpha=.79)$. For the personal autonomy support measure, we similarly formed an aggregate score by taking the mean of personal autonomy support felt across all four conditions $(\alpha=91)$. We assessed Discrimination ( $\alpha=.82$ ) using the same 3 items from Experiment 1a. We assessed group identification with respect to one's LGBTQ+ community as a whole using 3 items for each sub-dimension of the Cameron (2004) scale: ingroup ties ( $\alpha=.81)$, ingroup identity centrality $(\alpha=.79)$, and ingroup $\operatorname{affect}(\alpha=.84)$.

\section{Results}

Descriptive statistics including inter-scale correlations and grand means are summarized in Table 5.

\section{Writing Check and Potentially Overlapping Variables. As expected, LGBTQ+} community members reported less collective autonomy restriction in the collective autonomy support $(M=4.18, S D=1.14)$ versus collective autonomy restriction condition $(M=4.84 ; S D=$ 1.16), $F(1,394)=33.22, p<.001, \eta_{2}=.08$. Participants in the collective autonomy support condition $(M=5.36, S D=1.21)$ also reported significantly less discrimination than participants in 
the collective autonomy restriction condition $(M=5.67, S D=1.26), F(1,394)=6.16, p=.014$, $\eta_{2}=.02$. Participants in the collective autonomy support $(M=4.80, S D=1.32)$ and collective autonomy restriction $(M=4.65, S D=1.25)$ conditions did not significantly differ in their perceptions of receiving personal autonomy support from close others in their interpersonal interactions aggregated across the four interpersonal contexts, $F(1,394)=1.38, p=.242, \eta_{2}=.003$. We also did not find any effects of condition on personal autonomy support within any of the specific interpersonal contexts (See Table 6).

Openness about Sexual or Gender Identity. Participants in the collective autonomy support condition $(M=4.60 ; S D=1.63)$ and restriction condition $(M=4.42 ; S D=1.55)$ did not differ significantly in how open they felt they could be about their sexual or gender identity across parental, friendship, school peer, or co-worker environments (i.e., an aggregated score of openness across all 4 contexts was used); $F(1,394)=1.33, p=.249, \eta_{2}=.003$. The effect of condition was also non-significant for openness in each specific context (See Table 6).

Personal Autonomous Need Satisfaction. Participants assigned to the collective autonomy support condition reported feeling significantly greater personal autonomous need satisfaction $(M=5.06, S D=1.15)$ than those assigned to the collective autonomy restriction condition $(M=4.23, S D=1.30) ; F(1,396)=44.26, p<.001, \eta 2=.10$. This effect was robust controlling for personal autonomy support (aggregated across all four interpersonal contexts), group discrimination, and the extent to which LGBTQ+ individuals felt that they could be open about their gender/sexual identity (aggregated across all four interpersonal contexts): $F(1,391)=43.27, p<.001, \eta_{2}=.10$

Psychological Well-Being. Participants assigned to the collective autonomy support condition $(M=5.05, S D=1.15)$ reported experiencing significantly greater psychological well- 
being than participants assigned to the collective autonomy restriction condition $(M=4.18$, $S D=1.31), F(1,394)=49.99, p<.001, \eta_{2}=.11$. This effect remained robust when controlling for personal autonomy support, group discrimination, and openness about one's sexuality or gender, $F(1,391)=47.43, p<.001, \eta_{2}=.11$.

When testing simple-mediation, we found a significant indirect effect of the writing manipulation on psychological well-being through personal autonomous need satisfaction, indirect effect $=.54, S E=.09,95 \%$ BSCI $[.37, .72]$. The direct effect of condition on psychological well-being was also significant, $b=.34, S E=.10, p<.001,95 \%$ CI $[.14, .54] 15$. The indirect effect was also robust when controlling for discrimination, personal autonomy support, and openness about sexuality/gender, indirect effect $=.39, S E=.07,95 \%$ BSCI [.27, .53]. We also tested a multiple-mediation model in which we included the possible indirect effects of condition on psychological well-being through personal autonomy support, discrimination, and openness, as well as personal autonomous need satisfaction (entered in parallel). The indirect paths through personal autonomous need satisfaction $(.45,95 \%$ BSCI $[.30, .61])$ and perceived discrimination $(.04,95 \%$ BSCI $[.01, .09])$ were significant, while the indirect paths through personal autonomy support $(.03,95 \%$ BSCI $[-.02, .09])$, and openness $(.00,95 \%$ BSCI $[-.02, .02])$ were nonsignificant.

Moderation by Group Identification. We tested the same regression models described in Experiment 1. The effect of ingroup affect was significant such that individuals who felt high (versus low) levels of positive affect towards their group membership experienced greater

15 We tested a reverse pathway in which writing task condition impacted personal autonomous need satisfaction through changes in psychological well-being. We found that the indirect effect of condition on personal autonomous need satisfaction through well-being is significant: Indirect Effect $=.57[.41, .74]$. The direct effect of condition on personal autonomous need satisfaction was significant in the model, direct effect $=.25$, se $=.10, p=.011,95 \% \mathrm{CI}$. .06 , $.45]$. 
personal autonomous need satisfaction $(b=.31, s e=.06, t(395)=5.50, p<.001,95 \% \mathrm{CI}[.20, .42])$.

Feeling ties to other group members was also positively associated with autonomous need satisfaction, $(b=.16, s e=.05, t(395)=3.16, p<.001,95 \% \mathrm{CI}[.06, .27])$. In contrast, ingroup identity centrality was significantly negatively associated with personal autonomous need satisfaction $(b=-.26, s e=.05, t(395)=-5.52, p<.001,95 \% \mathrm{CI}[-.36,-.17])$. However, the interactions between condition and all three indicators of group identification were non-significant (all $t s<1.00$ ). Condition had a significant impact on personal autonomous need satisfaction for individuals +1 or -1 SDs above and below the mean of each of the three indicators of group identification.

Positive ingroup affect was significantly associated with psychological well-being, such that individuals who felt more positive about their group membership experienced greater psychological well-being $(b=.24, s e=.06, t(395)=4.09, p<.001,95 \% \mathrm{CI}[.12, .35])$. Feeling close ties to other ingroup member was also positively associated with greater psychological wellbeing $(b=.14, s e=.05, t(395)=2.56, p=.011,95 \% \mathrm{CI}[.03, .24])$. Ingroup identity centrality however was negatively associated with psychological well-being $(b=-.22, s e=.15, t(395)=-4.48$, $p<.00195 \% \mathrm{CI}[-.32,-.12])$. However, the two-way interactions between condition and the 3 different indicators of group identification were all non-significant (all $t s<1.00$ ). Condition had a significant impact on psychological well-being for individuals +1 or -1 SDs above and below the mean of each of the three indicators of group identification.

\section{Discussion}

In Experiment 2 we fully replicated the key findings of Experiment $1 \mathrm{a}-1 \mathrm{~b}$ using state level measures of personal autonomous need satisfaction and psychological well-being: LGBTQ+ individuals who were first asked to describe a way in which they felt their LGBTQ+ community had (versus lacked) collective autonomy reported significantly greater personal 
autonomous need satisfaction and psychological well-being immediately after. Moreover, mediation analysis revealed that the writing task indirectly effected psychological well-being through increases in personal autonomous need satisfaction. Also consistent with Experiment 1a and $1 \mathrm{~b}$, all of these effects were robust when we accounted for the potential effects which our manipulation may have had on participants' perceptions of anti-group discrimination, receiving personal autonomy support in interpersonal contexts, and feeling open to express one's LGBTQ+ identity in interpersonal contexts. However, we note that participants in the support (versus restriction) condition also experienced significantly lower anti-group discrimination, and this in turn, also had a significant indirect impact on psychological well-being.

In Experiment 2, we did not replicate the interaction between ingroup affect and our experimental manipulation: community members who felt relatively high and low levels of positive affect towards their LGBTQ+ community appeared to be both equivalently and significantly impacted by the collective autonomy manipulation.

\section{General Discussion}

Across three experiments, we found consistent evidence showing LGBTQ+ individuals' personal autonomous need satisfaction and psychological well-being is positively associated with perceiving their LGBTQ+ community can freely express its collective identity. LGBTQ+ individuals recruited locally from a Canadian city (Experiment 1a), and nationally from the United States (Experiment 1b) retrospectively recounted experiencing significantly greater personal autonomous need satisfaction when asked to recall a time in which they felt their community experienced collective autonomy support (versus restriction). In turn, greater personal autonomous need satisfaction, stemming from collective autonomy support (versus restriction) was associated with greater psychological well-being. A third independent sample of 
LGBTQ+ individuals recruited from the US (Experiment 2) reported feeling significantly greater state levels of personal autonomous need satisfaction and psychological well-being immediately after they were asked to describe how their LGBTQ+ community presently has (versus lacks) collective autonomy. Importantly, these effects were robust. That is, the aforementioned associations remained significant when controlling for whether people felt their personal autonomy was supported within their interpersonal relationships, whether they felt personally welcomed to be open about their sexual or gender identity, and whether they felt the LGBTQ+ community was a target of discrimination.

The relation between collective autonomy support (versus restriction) and personal autonomous need satisfaction and psychological well-being was also robust whether or not LGBTQ+ individuals felt relatively high or low levels of group identification with their LGBTQ+ community. At the same time, however, we found evidence in Experiment 1 (but not Experiment 2) showing the relation between collective autonomy restriction and personal autonomous need satisfaction and psychological well-being to be especially strong among LGBTQ+ individuals who are relatively highly identified with their LGBTQ+ community in terms of feeling positive affect towards their group membership. Thus, while perceptions of collective autonomy support (versus restriction) seem to be robustly consequential for all LGBTQ+ individuals regardless of their identification, we find some evidence (in Experiment 1 but not Experiment 2) that group members who are highly emotionally invested in their community might be the most affected.

\section{Implications}

By applying an intergroup SDT perspective to understand the challenges to psychological well-being faced by LGBTQ+ community members, we extend previous research which 
highlighted the important role of feeling personally autonomy supported in interpersonal contexts for psychological well-being (e.g., with family, friends, school peers, and work collogues; Legate et al., 2012, 2017). Our work demonstrates how perceiving the group's autonomy to be supported in broader society is also important for personal autonomous need satisfaction and psychological well-being. This finding adds empirical support to Ryan and colleagues (2017) intergroup perspective that LGBTQ+ individuals are psychologically impacted both by their personal experiences, as well as, by the collective reality of their community. Moreover, this finding is consistent with research documenting how group members' perception that they personally are discriminated against is distinct from whether they perceive that their group as a whole is the target of discrimination (Taylor et al., 1990). A potentially fruitful avenue for future research is to explicitly document possible discrepancies between whether people feel they are personally supported (versus restricted) as members of their community, and whether they feel their community as a whole is supported (versus restricted).

The present research also provides an important extension to research that has examined the psychological consequences of collective autonomy for people's personal autonomous need satisfaction and psychological well-being in the context of ethnic, racial, religious or national identities (Kachanoff et al., 2019). By extending a group-focused perspective within the context of gender or sexual identities, we provide further insights as to when LGBTQ+ individuals might experience optimal personal autonomous need satisfaction and psychological well-being (Legate et al., 2012, 2017).

We also extend past research by Kachanoff and colleagues (2019) by providing some evidence that the ingroup affect component of group identification may moderate the relation between collective autonomy and personal autonomous need satisfaction (in Experiment 1 but 
not Experiment 2). This result is consistent with research suggesting that group members who are highly identified are especially reactive to perceived group-based injustices. For example, among striking students, Giguère and Lalonde (2011) found ingroup affect was the only component of identification that was directly associated with collective action. At the same time, however, it was also the case that feeling positive affect towards one's group was overall positively associated with experiencing greater personal autonomous need satisfaction and psychological well-being (this result was robust in Experiment 1 and Experiment 2). This finding is consistent with previous research showing that group identification is, overall, positively associated with psychological well-being amongst marginalized group members (Bockting, et al., 2013; Schmitt, et al., 2014); as well as work suggesting that positive and internalized identification with one's social group is positively associated with need satisfaction and psychological well-being (Amiot \& Aubin, 2013; Greenaway, et al., 2017). Thus, an interesting paradox emerges: although higher levels of positive ingroup affect may have direct positive implications for group members' personal autonomous need satisfaction and psychological wellbeing, higher levels of positive ingroup affect may also place group members at greater risk of having their personal sense of autonomy thwarted in relation to restrictions being placed on their group.

Notably, the interaction effect observed in Experiment 1 using a retrospective method, did not replicate in Experiment 2 when we assessed state-level need-satisfaction and well-being. It is possible that the interaction effect observed in Experiment 1 is due to the retrospective framing of that experiment: people who feel stronger positive emotions towards their group are more likely to assume in hind sight that they would be psychologically impacted by their group's collective autonomy. However, as we show in Experiment 2, both individuals with high and low 
positive affect might actually be similarly impacted by collective autonomy support (or restriction) at the time they experience it. To shed light on these complexities, future research should probe possible mechanisms by which group members high in ingroup affect become especially influenced by the restrictions placed on their group's collective autonomy.

It is also important to note that even in Experiment 1, people who felt relatively low levels of positive ingroup affect were also still significantly influenced by restrictions placed on their group (even if less so than those with strong positive affect). Moreover, it was somewhat surprising that both ingroup ties and ingroup identity centrality did not moderate the effects of collective autonomy support (versus restriction) in Experiment 1 or Experiment 2. This runs counter to past research that has found gender-based discrimination to be especially destructive to individuals who perceive their gender identity to be central to their overall sense of self (McLemore, 2018). Thus, it is possible that once people can be categorized as belonging to a certain group, they will be personally impacted by the restrictions they perceive to be placed on their group, even if they feel negatively or deidentified toward their group.

On an applied level, although LGBTQ+ individuals are becoming more widely accepted in Western society (Tankard \& Paluck, 2017), some prominent political figures, religious figures, and mental health practitioners (Mallory, et al., 2018), still signal to the LGBTQ+ community that they should change who they are as a people (either in terms of their gender expression or their sexuality). The present research speaks to the importance of systemwide initiatives amongst trusted social institutions, such as government and medical institutions, to provide a clear message to the LGBTQ+ community that they are free and welcome in society to express all aspects of their sexual and gender identity. 


\section{Caveats and Future Directions}

The lack of a total effect of the writing task on psychological well-being in Experiment 1a is consistent with past research which finds that experimental manipulations of collective autonomy restriction have an indirect effect on group members' psychological well-being through personal autonomous need satisfaction, rather than a direct or total effect (Kachanoff et al., 2019, Study 3). Total effects of an independent variable on a distal outcome can be difficult to detect as they require high levels of statistical power, and thus, it is recommended to also examine the indirect effect of the independent variable through the proposed mediator (Kenny \& Judd, 2014; Rucker, Preacher, Tormala, \& Petty 2011).

Intriguingly however, unlike Experiment 1a, we found a significant total effect of the collective autonomy condition on psychological well-being in Experiment $1 \mathrm{~b}$ and Experiment 2. This discrepancy may be due to the Qualtrics and Mturk samples being older than the community sample recruited in Experiment 1a which largely consisted of University Students: Older participants in Experiment 1b may have reflected on periods in which the restrictions placed on LGBTQ+ communities were more severe (Tankard \& Paluck, 2017). However, this explanation of age cannot explain the significant main effect of condition on psychological wellbeing observed in Experiment 2, given that participants were instructed to describe the collective autonomy of the LGBTQ+ community in present-day America. Alternatively, it is possible that the influence of collective autonomy restriction on well-being was stronger amongst Americans living in a post-Trump era associated with heightened anti-LGBTQ+ rhetoric, versus the Canadian sample. Future work is needed in this area to explore these differences.

In the present work, we treated psychological well-being as an outcome variable in our mediation model. We did so in light of a large amount of research that suggests personal 
autonomous need satisfaction is an antecedent of well-being (Ryan \& Deci, 2017). However, because we only experimentally varied the $\mathrm{X}$ variable (collective autonomy support versus restriction) in the mediation model, and simultaneously measured the $\mathrm{M}$ (personal autonomous need satisfaction) and Y (psychological well-being) variables, we cannot infer a causal pathway between $\mathrm{M}$ and $\mathrm{Y}$ in the present work. In Experiment $1 \mathrm{~b}$ and Experiment 2 (but not Experiment 1a) we find evidence of a feedback pathway in which psychological well-being mediated the relationship between the writing task and personal autonomous need satisfaction. Future work will be needed to directly explore this potential reverse pathway.

We acknowledge the possibility that the writing manipulation could have influenced personal autonomous need satisfaction by priming a supported (versus restricted) sense of having autonomy in general, rather than a sense of collective autonomy support (versus restriction) specific to one's LGBTQ+ community. Importantly, however, our data provides some evidence to rule out this concern. Specifically, the collective autonomy manipulation did not consistently relate to perceptions of having/lacking personal autonomy within interpersonal interactions across the three experiments (as would be expected if our manipulation primed autonomy support (versus restriction) in general). It was only in Experiment $1 \mathrm{~b}$ that we observed some marginal evidence that people's perceptions of receiving personal autonomy support within less intimate interpersonal contexts (i.e., with peers or co-workers) might by marginally related to their perception that their LGBTQ+ community as a whole is supported. As such, we have confidence that our manipulation was specific to the collective autonomy of one's LGBTQ+ community.

Relatedly, the effects of condition on well-being may be partially attributable to participants broadly recounting more positive (non-discriminatory) versus negative 
(discriminatory) intergroup experiences in the collective autonomy support (versus restriction) condition. Theoretically, feeling that other groups attempt to restrict their ingroup's collective autonomy should be expected to be experienced as discrimination to some extent. Consistent with this, we observed a marginal effect of condition on discrimination in Experiment 1a and a significant effect of condition on discrimination in Experiment 2 (in which we had greater statistical power). Thus, changes in overall perceived discrimination against the group which might result from collective autonomy support (versus restriction) could be an additional way in which collective autonomy is consequential for psychological well-being (beyond its impact through personal autonomous need satisfaction). Importantly however, we replicated in both experiments that assignment to the writing task was significantly indirectly related to psychological well-being through personal autonomous need satisfaction, even when accounting for the potential effects that condition might have had on psychological well-being by eliciting perceptions of discrimination more broadly. We also note that a limitation of this work was that we did not include a measure of discrimination in Experiment $1 \mathrm{~b}$.

The experimental design used in the present research was also limited in that there was no "no writing" control comparison condition. Thus, it is unclear whether writing about collective autonomy restriction reduces personal autonomous need satisfaction and psychological well-being, and/or, whether writing about collective autonomy support increases personal autonomous need satisfaction and psychological well-being (or a combination of both possibilities).

\section{Conclusion}

As with heterosexual and cisgender individuals, LGBTQ+ people have a basic psychological need to express their own sexual and/or gender identity, which also binds them as 
a larger community of people who fall under the LGBTQ+ umbrella (Ryan, et al., 2017). By applying self-determination theory to the intergroup level, we showed that for LGBTQ+ individuals to satisfy their need for personal autonomy, they must not only feel personally supported by the personal relationships in their life, but also feel that their LGBTQ+ community is free to define and express its collective identity. 


\section{References}

Adler, M., \& Raz, G. (Narrators). (2009, June 28). 40 years later, Stonewall riots remembered [radio broadcast]. In K. Young (Producer), All Things Considered. Washington, DC: National Public Radio.

Amiot, C. E., \& Aubin, R. M. (2013). Why and how are you attached to your Social Group? Investigating different forms of social identification. British Journal of Social Psychology, 52, 563-586. DOI: $10.1111 /$ bjso.12004

Amiot, C. E., \& Sansfaçon, S. (2011). Motivations to identify with social groups: A look at their positive and negative consequences. Group Dynamics: Theory, Research, and Practice, 15, 105127. DOI: $10.1037 / \mathrm{a} 0023158$

Bauer, H., Mahn, C. (2014). Introduction: transnational lesbian cultures. Journal of Lesbian Studies, 18(3), 203-208. doi:10.1080/10894160.2014.896608

Bockting, W. O., Miner, M. H., Swinburne Romine, R. E., Hamilton, A., \& Coleman, E. (2013). Stigma, mental health, and resilience in an online sample of the US transgender population. American Journal of Public Health, 103(5), 943-951.doi:10.2105/AJPH.2013.301241

Burrelli, D. F., \& Feder, J. (2009). Homosexuals and the U.S. Military: Current Issues [Congressional Research Service Report for Congress]. Congressional Research Service.

Burton, C. M., Marshal, M. P., Chisolm, D. J., Sucato, G. S., \& Friedman, M. S. (2013). Sexual minority-related victimization as a mediator of mental health disparities in sexual minority youth: A longitudinal analysis. Journal of Youth and Adolescence, 42, 394-402. DOI:

$10.1007 / \mathrm{s} 10964-012-9901-5$ 
Branscombe, N. R., Schmitt, M. T., \& Harvey, R. D. (1999). Perceiving pervasive discrimination among African Americans: Implications for group identification and well-being. Journal of Personality and Social Psychology, 77, 135-149. doi: 10.1037/0022-3514.77.1.135

Brown, G. (2007). Mutinous eruptions: Autonomous spaces of radical queer activism. Environment and Planning a Environ Plan A, 39, 2685-2698.

Bruneau, E., Szekeres, H., Kteily, N., Tropp, L. R., \& Kende, A. (2019). Beyond dislike: Blatant dehumanization predicts teacher discrimination. Group Processes \& Intergroup Relations, DOI: $10.1177 / 1368430219845462$

Callaghan, T.D. (2007). Contra/diction: How catholic doublespeak in Canadian Catholic secondary schools furthers homophobia. The Canadian On-Line Journal of Queer Studies in Education, 3, 1-22.

Cameron, J. E. (2004). A three-factor model of social identity. Self and Identity, 3, 239-262. DOI: $10.1080 / 13576500444000047$

Chen, B., Van Assche, J., Vansteenkiste, M., Soenens, B., \& Beyers, W. (2015). Does psychological need satisfaction matter when environmental or financial safety are at risk? Journal of Happiness Studies, 16, 745-766. DOI: 10.1007/s10902-014-9532-5

Chirkov, V., Ryan, R. M., Kim, Y., \& Kaplan, U. (2003). Differentiating autonomy from individualism and independence: A self-determination theory perspective on internalization of cultural orientations and well-being. Journal of Personality and Social Psychology, 84, 97-110. DOI: $10.1037 / 0022-3514.84 .1 .97$

D’Augelli, A. R. (2002). Mental health problems among lesbian, gay, and bisexual youths ages 14 to 21. Clinical Child Psychology and Psychiatry, 7, 433-456.

Deci, E. L., Olafsen, A. H., \& Ryan, R. M. (2017). Self-determination theory in work 
organizations: The state of a science. Annual Review of Organizational Psychology and Organizational Behavior, 4, 19-43. Doi: /10.1146/annurev-orgpsych-032516-113108

Delgardo, D. (2019, November 9). I served 30 years in the military. Trump's Transgender ban calls me unfit. Time Magazine. Retrieved from https://time.com/5721582/transgender-militaryveterans-day/

DeStefano, M. (2019, January 30). High school could have been hell for my transgender son. Don't make it hell for the next kid. USA Today. Retrieved from https://www.usatoday.com/story/opinion/voices/2019/01/30/transgender-bathroom-debatesupreme-court-column/2708594002/

Detrie, P. M., \& Lease, S. H. (2007). The relation of social support, connectedness, and collective self-esteem to the psychological well-being of lesbian, gay, and bisexual youth. Journal of Homosexuality, 53(4), 173-199. doi:10.1080/00918360802103449

Diener, E., Emmons, R. A., Larsen, R. J., \& Griffin, S. (1985). The satisfaction with life scale. Journal of Personality Assessment, 49, 71-75. DOI:10.1207/s15327752jpa4901_13

Giguère, B., \& Lalonde, R. N. (2010). Why do students strike? Direct and indirect determinants of collective action participation. Political Psychology, 31, 227-247. DOI: 10.1111/j.14679221.2009.00750.x

Goh, J. X., Kort, D. N., Thurston, A. M., Benson, L. R., \& Kaiser, C. R. (2019). Does concealing a sexual minority identity prevent exposure to prejudice? Social Psychological and Personality Science, DOI:10.1177/1948550619829065

Górska, P., \& Bilewicz, M. (2015). When “a Group in Itself” becomes “a Group for Itself”: Overcoming Inhibitory Effects of Superordinate Categorization on LGBTQ Individuals: When 
“a Group in Itself” becomes “a Group for Itself." Journal of Social Issues, 71(3), 554-575. DOI:

10.1111/josi. 12128

Guidotto, N. (2005). Sharing scars, healing ourselves: Theory in praxis. Canadian Online Journal for Queer Studies in Education, 3, 1-17.

Greenaway, K.H., Amiot, C.E., Louis, W.R., \& Bentley, S. (2017). The role of psychological need satisfaction in promoting student identification. In K.I. Mavor, M. Platow, \& B. Bizumic (Eds.), Self and Social Identity in Educational contexts, pp.176-192. Abingdon: Routledge.

Hayes, A. F. (2017). Introduction to mediation, moderation, and conditional process analysis: A regression-based approach (Second Edition). New York: The Guilford Press.

Herek, G. M. (2009). Hate crimes and stigma-related experiences among sexual minority adults in the United States: Prevalence estimates from a national probability sample. Journal of interpersonal violence, $24,54-74$.

Kachanoff, F.J., Kteily, N., Khullar, T., Park, H.J., \& Taylor, D.M., (in press). Determining our destiny: Do restrictions to collective autonomy fuel collective action. Journal of Personality and Social Psychology. doi: 10.1037/pspi0000217

Kachanoff, F.J., Wohl, M.J.A., Koestner, R., \& Taylor, D.M., (2020). Them, Us, and I: How group contexts influence basic psychological needs. Current Directions in Psychological Science.29, 47-54. DOI: 10.1177/0963721419884318

Kachanoff, F. J., Taylor, D. M., Caouette, J., Khullar, T. H., \& Wohl, M. J. A. (2019).

The chains on all my people are the chains on me: Restrictions to collective autonomy undermine the personal autonomy and psychological well-being of group members. Journal of Personality and Social Psychology. DOI: 10.1037/pspp0000177 
Kachanoff, F.J., Ysseldyk, R., Taylor, D.M., de la Sablonnière, R., Crush, J., (2016). The good, the bad, and the central of group identification: Evidence of a $\mathrm{U}$-shaped quadratic relation between ingroup affect and identity centrality. European Journal of Social Psychology, 46, 563-580. DOI:1002/ejsp.2199

Kenny, D.A., \& Judd, C.M. (2014). Power anomalies in testing mediation. Psychological Science, 25, 334-339. DOI:10.1177/0956797613502676

King, M., Semlyen, J., Tai, S. S., Killaspy, H., Osborn, D., Popelyuk, D., \& Nazareth, I. (2008). A systematic review of mental disorder, suicide, and deliberate self-harm in lesbian, gay and bisexual people. BMC Psychiatry, 8. DOI: 10.1186/1471-244X-8-70

Kitzinger, C., \& Wilkinson, S. (1994). Virgins and queers: Rehabilitating heterosexuality? Gender \& Society, 8, 444-462. DOI:10.1177/089124394008003009

Legate, N., Ryan, R. M., \& Rogge, R. D. (2017). Daily autonomy support and sexual identity disclosure predicts daily mental and physical health outcomes. Personality and Social Psychology Bulletin, 43, 860-873. DOI: 10.1177/0146167217700399

Legate, N., Ryan, R. M., \& Weinstein, N. (2012). Is coming out always a “Good Thing”? Exploring the relations of autonomy support, outness, and wellness for Lesbian, Gay, and Bisexual individuals. Social Psychological and Personality Science, 3, 145-152. DOI:

$10.1177 / 1948550611411929$

Levin, D. (2019, July 23). North Carolina Reaches Settlement on “Bathroom Bill”: Transgender people cannot be prevented from using bathrooms that match their gender identity in public buildings. Retrieved from https://www.nytimes.com/2019/07/23/us/north-carolina-transgenderbathrooms.html 
McLean, K. (2008). Inside, outside, nowhere: Bisexual men and women in the gay and lesbian community. Journal of Bisexuality, 8, 63-80. DOI:10.1080/15299710802143174

McLemore, K. A. (2018). A minority stress perspective on transgender individuals' experiences with misgendering. Stigma and Health, 3, 53. DOI:10.1037/sah0000070

Mallory, C., Brown, T. N. T., \& Conron, K. J. (2018). Conversion Therapy and LGBT Youth. The Williams Institute UCLA School of Law. Retrieved from https://williamsinstitute.law.ucla.edu/wp-content/uploads/Conversion-Therapy-LGBT-YouthJan-2018.pdf

Mulé, N. (2006, May 5). Equality's limitations, liberation's challenges: Considerations for queer movement strategizing. Canadian Online Journal of Queer Studies in Education, 2(1). Available: http://jqstudies.oise.utoronto.ca/journal/viewarticle.php?id=26

Neufeld, S. D., \& Schmitt, M. T. (2019). Solidarity Not Homogeneity: Constructing a Superordinate Aboriginal Identity That Protects Subgroup Identities. Political Psychology, 40, 599-616.

Nicolosi, J. (1991). Reparative therapy of male homosexuality: A new clinical approach. Lanham, MD, US: Jason Aronson.

Oyserman, D. (2007). Social identity and self-regulation. In A. Kruglanski, \& T. Higgins (Eds.), Social Psychology: Handbook of basic principles (pp. 432-453). New York, NY: Guilford Press.

Pachankis, J. E. (2007). The psychological implications of concealing a stigma: A cognitiveaffective-behavioral model. Psychological Bulletin, 133, 328-345. DOI:10.1037/00332909.133.2.328 
Parker, P., Ryan, R., Duineveld, J., \& Bradshaw, E. (2019, April 18). Validation of the social identity group need satisfaction and frustration scale. Unpublished Manuscript available at https://doi.org/10.31234/osf.io/ycbwe

Paterson, J. L., Brown, R., \& Walters, M. A. (2018). Understanding victim group responses to hate crime: Shared identities, perceived similarity and intergroup emotions. TPM - Testing, Psychometrics, Methodology in Applied Psychology, 25, 163-177. DOI: 10.4473/TPM25.2.1

Paterson, J. L., Brown, R., \& Walters, M. A. (2019). The short and longer term impacts of hate crimes experienced directly, indirectly, and through the media. Personality and Social Psychology Bulletin, 45, 994-1010. DOI: 10.1177/0146167218802835

Quinn, D. M., \& Earnshaw, V. A. (2011). Understanding concealable stigmatized identities: The role of identity in psychological, physical, and behavioral outcomes. Social Issues and Policy Review, 5, 160-190. DOI: 10.1111/j.1751-2409.2011.01029.x

Radloff, L. (1977). The CES-D scale: A self-report depression scale for research in the general population. Applied Psychological Measurement, 1, 385-401. DOI: $10.1177 / 014662167700100306$

Roth, G., Assor, A., Niemiec, C. P., Ryan, R. M., \& Deci, E. L. (2009). The emotional and academic consequences of parental conditional regard: Comparing conditional positive regard, conditional negative regard, and autonomy support as parenting practices. Developmental Psychology, 45, 1119-1142. DOI:10.1037/a0015272

Rosenberg, M. (1965). Society and the adolescent self-image. Princeton, NJ: Princeton University Press.

Rucker, D. D., Preacher, K. J., Tormala, Z. L., \& Petty, R. E. (2011). Mediation analysis in social psychology: Current practices and new recommendations. Social and Personality Psychology 
Compass, 5, 359-371. DOI: 10.1111/J.1751-9004.2011.00355.x

Ryan, R. M., \& Deci, E. L. (2017). Self-Determination Theory: Basic Psychological Needs in Motivation, Development, and Wellness. New York: The Guilford Press.

Ryan, W. S., Hunger, J. M., \& Major, B. (2017). Applying intergroup relations research to understanding LGB health disparities. Journal of Social Issues, 73, 477-492. DOI: $10.1111 /$ josi. 12227

Ryan, W. S., Legate, N., \& Weinstein, N. (2015). Coming out as Lesbian, Gay, or Bisexual: The lasting impact of initial disclosure experiences. Self and Identity, 14, 549-569. DOI: $10.1080 / 15298868.2015 .1029516$

Ryan, W. S., Legate, N., Weinstein, N., \& Rahman, Q. (2017). Autonomy support fosters Lesbian, Gay, and Bisexual identity disclosure and wellness, especially for those with internalized Homophobia. Journal of Social Issues, 73, 289-306. DOI: 10.1111/josi.12217

Schmitt, M. T., Branscombe, N. R., Postmes, T., \& Garcia, A. (2014). The consequences of perceived discrimination for psychological well-being: A meta-analytic review. Psychological Bulletin, 140, 921-948. DOI: 10.1037/a0035754

Semlyen, J., King, M., Varney, J., \& Hagger-Johnson, G. (2016). Sexual orientation and symptoms of common mental disorder or low well-being: combined meta-analysis of 12 UK population health surveys. BMC Psychiatry, 16. DOI: 10.1186/s12888-016-0767-z

Sheldon, K. M., \& Gunz, A. (2009). Psychological seeds as basic motives, not just experiential requirements. Journal of Personality, 77, 1467-1492.

Spielberger, C. D., Jacobs, G., Russell, S., \& Crane, R. (1983). Assessment of anger: The State-Trait Anger Scale. In J. N. Butcher \& C. D. Spielberger (Eds.), Advances in personality assessment (Vol. 2, pp. 159-187). Hillsdale, NJ: Lawrence Erlbaum. 
Tajfel, H., \& Turner, J. C. (1979). An integrative theory of intergroup conflict. In W. G.

Worchel, \& S. Austin (Eds.), The social psychology of intergroup relations (pp. 33-47). Monterey, CA: Brooks/Cole.

Tankard, M. E., \& Paluck, E. L. (2017). The effect of a Supreme Court decision regarding gay marriage on social norms and personal attitudes. Psychological science, 28, 1334-1344. DOI: $10.1177 / 095679761770959$

Taylor, D. M., Wright, S. C., Moghaddam, F. M., \& Lalonde, R. N. (1990). The personal/group discrimination discrepancy: Perceiving my group, but not myself, to be a target for discrimination. Personality and social psychology bulletin, 16, 254-262. DOI: $10.1177 / 0146167290162006$

Van Petegem, S., Soenens, B., Vansteenkiste, M., \& Beyers, W. (2015). Rebels with a cause? Adolescent defiance from the perspective of reactance theory and self-determination theory. Child Development, 86, 903-918. doi:10.1111/cdev.12355

Van Zomeren, M., Postmes, T., \& Spears, R. (2008). Toward an integrative social identity model of collective action: A quantitative research synthesis of three socio-psychological perspectives. Psychological Bulletin, 134, 504-535. DOI: /10.1037/0033-2909.134.4.504

Van Zomeren, M., Spears, R., \& Leach, C. W. (2008). Exploring psychological mechanisms of collective action: Does relevance of group identity influence how people cope with collective disadvantage? British Journal of Social Psychology, 47, 353-372

DOI:10.1348/014466607X231091

Verkuyten, M., \& Yogeeswaran, K. (2017). The social psychology of intergroup toleration: A roadmap for theory and research. Personality and Social Psychology Review, 21, 72-96. DOI: $10.1177 / 1088868316640974$ 
Weinstein, N., Przybylski, A. K., \& Ryan, R. M. (2012). The index of autonomous functioning:

Development of a scale of human autonomy. Journal of Research in Personality, 46, 397-413. DOI: $10.1016 /$ j.jrp.2012.03.007

Weinstein, N., Ryan, W. S., DeHaan, C. R., Przybylski, A. K., Legate, N., \& Ryan, R. M (2012). Parental autonomy support and discrepancies between implicit and explicit sexual identities: Dynamics of self-acceptance and defense. Journal of Personality and Social Psychology, 102, 
Table 1. Means, Standard Deviations and Pearson Correlations for All Variables (Experiment 1a)

\begin{tabular}{|c|c|c|c|c|c|c|c|c|c|c|}
\hline & Mean & $\begin{array}{l}\text { Standard } \\
\text { Deviation }\end{array}$ & 1 & 2 & 3 & 4 & 5 & 6 & 7 & 8 \\
\hline $\begin{array}{l}\text { 1. Collective Autonomy } \\
\text { Restriction }\end{array}$ & 4.60 & 1.26 & 1 & & & & & & & \\
\hline $\begin{array}{l}\text { 2. Personal Autonomous Need } \\
\text { Satisfaction }\end{array}$ & 4.25 & 1.30 & $-.35^{* * *}$ & 1 & & & & & & \\
\hline $\begin{array}{l}\text { 3. Psychological Well Being } \\
\text { (Life Satisfaction) }\end{array}$ & 4.14 & 1.32 & $-.18+$ & $.35^{* * *}$ & 1 & & & & & \\
\hline $\begin{array}{l}\text { 4. Anti-LGBTQ+ } \\
\text { Discrimination }\end{array}$ & 5.26 & 1.44 & $.62 * * *$ & $-.28 * *$ & $-.31 * * *$ & 1 & & & & \\
\hline $\begin{array}{l}\text { 5. Personal Autonomy } \\
\text { Support }\end{array}$ & 4.14 & 1.26 & -.07 & $.22 *$ & $.32^{* * *}$ & -.02 & 1 & & & \\
\hline $\begin{array}{l}\text { 6. Group Identification } \\
\text { (Ingroup Affect) }\end{array}$ & 5.63 & 1.32 & $0.16+$ & $.28^{* *}$ & 0.11 & 0.11 & $.22 *$ & 1 & & \\
\hline $\begin{array}{l}\text { 7. Group Identification } \\
\text { (Ingroup Member Ties) }\end{array}$ & 4.67 & 1.48 & 0.14 & 0.16 & -0.02 & 0.16 & 0.08 & $.44 * * *$ & 1 & \\
\hline $\begin{array}{l}\text { 8. Group Identification } \\
\text { (Ingroup Identity Centrality) }\end{array}$ & 4.96 & 1.52 & $.34 * * *$ & 0.05 & -0.10 & $.24 *$ & -0.10 & $.26^{* *}$ & $.52 * * *$ & 1 \\
\hline
\end{tabular}

Note. $\nmid p<.10,{ }^{*} \mathrm{p}<.05, * * \mathrm{p}<.01, * * * \mathrm{p}<.001$. Pairwise deletion was used for missing data. 
Table 2. Condition means and condition effects for all outcome variables (Experiment 1a)

\begin{tabular}{llcccc}
\hline & $\begin{array}{c}\text { Collective } \\
\text { Autonomy } \\
\text { Restriction } \\
\text { Condition }\end{array}$ & \multicolumn{2}{c}{$\begin{array}{c}\text { Collective } \\
\text { Autonomy } \\
\text { Support } \\
\text { Condition }\end{array}$} & \multicolumn{1}{c}{$\begin{array}{c}\text { Condition Effect } \\
\text { (ANOVA) }\end{array}$} \\
& M & SD & M & SD & \\
\hline $\begin{array}{l}\text { 1. Collective Autonomy } \\
\text { Restriction }\end{array}$ & 5.01 & 1.15 & 4.22 & 1.24 & $F(1,112)=12.19, p<.001, \eta^{2}=.10$ \\
$\begin{array}{l}\text { 2. Personal Autonomous Need } \\
\text { Satisfaction }\end{array}$ & 3.81 & 1.19 & 4.66 & 1.27 & $F(1,112)=13.62, p<.001, \eta^{2}=.11$ \\
$\begin{array}{l}\text { 3. Life Satisfaction } \\
\text { (Psychological Well Being) }\end{array}$ & 4.09 & 1.41 & 4.18 & 1.24 & $F(1,112)=.15, p=.701, \eta^{2}=.001$ \\
$\begin{array}{l}\text { 4. Anti-LGBTQ+ } \\
\text { Discrimination } \\
\text { 5. Personal Autonomy Support }\end{array}$ & 4.28 & 1.21 & 4.02 & 1.30 & $F(1,105)=1.75, p=.295, \eta^{2}=.01$ \\
\hline
\end{tabular}


Table 3. Means, Standard Deviations and Pearson Correlations for All Variables (Experiment 1b)

\begin{tabular}{|c|c|c|c|c|c|c|c|c|c|c|c|c|c|c|c|c|c|c|}
\hline & $M$ & $S D$ & 1 & 2 & 3 & 4 & 5 & 6 & 7 & 8 & 9 & 10 & 11 & 12 & 13 & 14 & 15 & 16 \\
\hline $\begin{array}{l}\text { 1. Collective Autonomy } \\
\text { Restriction }\end{array}$ & 4.09 & 1.31 & 1 & & & & & & & & & & & & & & & \\
\hline $\begin{array}{l}\text { 2. Personal Autonomous } \\
\text { Need Satisfaction }\end{array}$ & 4.92 & 1.40 & $-.40 * * *$ & 1 & & & & & & & & & & & & & & \\
\hline $\begin{array}{l}\text { 3. Psychological Well- } \\
\text { Being }\end{array}$ & 4.41 & 1.59 & $-.46 * * *$ & $.69 * * *$ & 1 & & & & & & & & & & & & & \\
\hline $\begin{array}{l}\text { 4. Sexuality }+ \text { Gender } \\
\text { Openness (All Contexts) }\end{array}$ & 4.31 & 1.81 & $-.26 * * *$ & $.39 * * *$ & $.34 * * *$ & 1 & & & & & & & & & & & & \\
\hline $\begin{array}{l}\text { 5. Sexuality + Gender } \\
\text { Openness (Parent) }\end{array}$ & 3.80 & 2.36 & $-.21^{* * *}$ & $.31^{* * *}$ & $.29^{* * *}$ & $.76^{* * *}$ & 1 & & & & & & & & & & & \\
\hline $\begin{array}{l}\text { 6. Sexuality + Gender } \\
\text { Openness (Friends) }\end{array}$ & 5.34 & 1.98 & $-.20^{* * *}$ & $.36^{* * *}$ & $.26^{* * *}$ & $.79^{* * * *}$ & $.44 * * *$ & 1 & & & & & & & & & & \\
\hline $\begin{array}{l}\text { 7. Sexuality + Gender } \\
\text { Openness (School) }\end{array}$ & 3.96 & 2.23 & $-.19^{* * *}$ & $.31^{* * *}$ & $.28^{* * *}$ & $.85^{* * *}$ & $.46 * * *$ & $.59^{* * *}$ & 1 & & & & & & & & & \\
\hline $\begin{array}{l}\text { 8. Sexuality + Gender } \\
\text { Openness (Work) }\end{array}$ & 4.01 & 2.27 & $-.26 * * *$ & $.29_{* * *}$ & $.32^{* * *}$ & $.87 * * *$ & $.52 * * *$ & $.59 * * *$ & $.72 * * *$ & 1 & & & & & & & & \\
\hline $\begin{array}{l}\text { 9. Personal Autonomy } \\
\text { Support (All Contexts) }\end{array}$ & 4.39 & 1.45 & $-.28 * * *$ & $.33^{* * *}$ & $.28 * * *$ & $.72 * * *$ & $.57 * * *$ & $.56^{* * *}$ & $.62 * * *$ & $.62^{* * *}$ & 1 & & & & & & & \\
\hline $\begin{array}{l}\text { 10. Personal Autonomy } \\
\text { Support (Parent) }\end{array}$ & 3.93 & 2.02 & $-.24 * * *$ & $.24^{* * *}$ & $.19^{* * *}$ & $.45^{* * *}$ & $.69^{* * *}$ & $.26 * * *$ & $.25 * * *$ & $.27 * * *$ & $.68^{* * * *}$ & 1 & & & & & & \\
\hline $\begin{array}{l}\text { 11. Personal Autonomy } \\
\text { Support (Friend) }\end{array}$ & 5.38 & 1.67 & $-.14 * *$ & $.24 * * *$ & $.14 * *$ & $.54 * * *$ & $.28 * * *$ & $.70^{* * *}$ & $.46^{* * *}$ & $.38 * * *$ & $.71 * * *$ & $.32 * *$ & 1 & & & & & \\
\hline $\begin{array}{l}\text { 12. Personal Autonomy } \\
\text { Support (School) }\end{array}$ & 3.99 & 1.95 & $-.26^{* * *}$ & $.24^{* * *}$ & $.25^{* * *}$ & $.63^{* * *}$ & $.37 * * *$ & $.39^{* * *}$ & $.67 * * *$ & $.58^{* * *}$ & $.83^{* * *}$ & $.30^{* * *}$ & $.49_{* * *}$ & 1 & & & & \\
\hline $\begin{array}{l}\text { 13. Personal Autonomy } \\
\text { Support (Work) }\end{array}$ & 4.13 & 1.92 & $-.24 * * *$ & $.28 * * *$ & $.30^{* * *}$ & $.64 * *$ & $.41 * * *$ & $.38 * * *$ & $.58 * * *$ & $.71^{* * *}$ & $.83^{* * *}$ & $.37 * * *$ & $.40 * * *$ & $.74 * * *$ & 1 & & & \\
\hline $\begin{array}{l}\text { 14. Group Identification } \\
\text { (Ingroup Affect) }\end{array}$ & 6.04 & 1.18 & -0.06 & $.24 * * *$ & $.19 * * *$ & $.20 * * *$ & $.13 *$ & $.30^{* * *}$ & 0.10 & $.15 * *$ & $.26^{* * *}$ & $.14 *$ & $.31 * * *$ & $.16^{* *}$ & $.18 * *$ & 1 & & \\
\hline $\begin{array}{l}\text { 15. Group Identification } \\
\text { (Ingroup Member Ties) }\end{array}$ & 4.86 & 1.79 & $-0.10 \nmid$ & 0.05 & 0.02 & $.26 * * *$ & $.22 * * *$ & $.26^{* * *}$ & $.20 * * *$ & $.19 * * *$ & $.26^{* * *}$ & $.22^{* * *}$ & $.24 * * *$ & $.23 * * *$ & $.16^{* *}$ & $.46^{* * *}$ & 1 & \\
\hline $\begin{array}{l}\text { 16. Group Identification } \\
\text { (Ingroup Identity } \\
\text { Centrality) }\end{array}$ & 4.29 & 1.64 & -0.08 & 0.03 & -0.01 & $.19^{* * * *}$ & $.14 * *$ & $.17 * *$ & $.16^{* *}$ & $.17 * *$ & $.14 * * *$ & 0.07 & $.18 * *$ & $.14 * *$ & $0.08 t$ & $.32 * * *$ & $.50^{* * *}$ & 1 \\
\hline
\end{tabular}

Note. $\nmid p<.10,{ }^{*} \mathrm{p}<.05,{ }^{*} \mathrm{p}<.01, * * * \mathrm{p}<.001$. Pairwise deletion was used for missing data. 
Table 4. Condition Means and Condition Effects for All Variables (Experiment 1b).

\begin{tabular}{|c|c|c|c|c|c|}
\hline & \multicolumn{2}{|c|}{$\begin{array}{l}\text { Collective } \\
\text { Autonomy } \\
\text { Restriction } \\
\text { Condition }\end{array}$} & \multicolumn{2}{|c|}{$\begin{array}{l}\text { Collective } \\
\text { Autonomy } \\
\text { Support } \\
\text { Condition }\end{array}$} & \multirow[t]{2}{*}{$\begin{array}{l}\text { Condition Effect } \\
\text { (ANOVA) }\end{array}$} \\
\hline & M & $\mathrm{SD}$ & M & $\mathrm{SD}$ & \\
\hline $\begin{array}{l}\text { 1. Collective Autonomy } \\
\text { Restriction }\end{array}$ & 4.39 & 1.23 & 3.76 & 1.33 & $F(1,367)=22.29, p<.001, \eta_{2}=.06$ \\
\hline $\begin{array}{l}\text { 2. Personal Autonomous } \\
\text { Need Satisfaction }\end{array}$ & 4.50 & 1.36 & 5.39 & 1.30 & $F(1,368)=40.89, p<.001, \eta_{2}=.10$ \\
\hline $\begin{array}{l}\text { 3. Psychological Well- } \\
\text { Being }\end{array}$ & 3.69 & 1.43 & 5.21 & 1.36 & $F(1,368)=110.11, p<.001, \eta^{2}=.23$ \\
\hline $\begin{array}{l}\text { 4. Sexuality }+ \text { Gender } \\
\text { Openness (All Contexts) }\end{array}$ & 4.13 & 1.85 & 4.50 & 1.75 & $F(1,368)=3.89, p=.049, \eta_{2}=.01$ \\
\hline $\begin{array}{l}\text { 5. Sexuality }+ \text { Gender } \\
\text { Openness (Parent) }\end{array}$ & 3.61 & 2.36 & 4.01 & 2.35 & $F(1,363)=2.54, p=.112, \eta_{2}=.007$ \\
\hline $\begin{array}{l}\text { 6. Sexuality }+ \text { Gender } \\
\text { Openness (Friends) }\end{array}$ & 5.23 & 2.05 & 5.47 & 1.90 & $F(1,368)=1.45, p=.229, \eta_{2}=.004$ \\
\hline $\begin{array}{l}\text { 7. Sexuality }+ \text { Gender } \\
\text { Openness (School) }\end{array}$ & 3.71 & 2.24 & 4.23 & 2.18 & $F(1,354)=4.89, p=.028, \eta_{2}=.014$ \\
\hline $\begin{array}{l}\text { 8. Sexuality }+ \text { Gender } \\
\text { Openness (Work) }\end{array}$ & 3.81 & 2.24 & 4.23 & 2.28 & $F(1,363)=3.14, p=.077, \eta_{2}=.009$ \\
\hline $\begin{array}{l}\text { 9. Personal Autonomy } \\
\text { Support (All Contexts) }\end{array}$ & 4.23 & 1.42 & 4.52 & 1.47 & $F(1,366)=2.83, p=.093, \eta_{2}=.008$ \\
\hline $\begin{array}{l}\text { 10. Personal Autonomy } \\
\text { Support (Parent) }\end{array}$ & 3.82 & 2.00 & 4.06 & 2.05 & $F(1,361)=1.26, p=.263, \eta_{2}=.003$ \\
\hline $\begin{array}{l}\text { 11. Personal Autonomy } \\
\text { Support (Friend) }\end{array}$ & 5.30 & 1.70 & 5.46 & 1.63 & $F(1,361)=.94, p=.334, \eta_{2}=.003$ \\
\hline $\begin{array}{l}\text { 12. Personal Autonomy } \\
\text { Support (School) }\end{array}$ & 3.81 & 1.91 & 4.19 & 1.97 & $F(1,345)=3.40, p=.066, \eta_{2}=.01$ \\
\hline $\begin{array}{l}\text { 13. Personal Autonomy } \\
\text { Support (Work) }\end{array}$ & 3.99 & 1.81 & 4.29 & 2.03 & $F(1,355)=2.27, p=.133, \eta_{2}=.006$ \\
\hline
\end{tabular}


Table 5. Means, Standard Deviations and Pearson Correlations for All Variables (Experiment 2)

\begin{tabular}{|c|c|c|c|c|c|c|c|c|c|c|c|c|c|c|c|c|c|c|c|}
\hline & $M$ & $S D$ & 1 & 2 & 3 & 4 & 5 & 6 & 7 & 8 & 9 & 10 & 11 & 12 & 13 & 14 & 15 & 16 & 17 \\
\hline $\begin{array}{l}\text { 1. Collective Autonomy } \\
\text { Restriction }\end{array}$ & 4.50 & 1.19 & 1 & & & & & & & & & & & & & & & & \\
\hline $\begin{array}{l}\text { 2. Personal Autonomous } \\
\text { Need Satisfaction }\end{array}$ & 4.66 & 1.29 & $-.41^{* * *}$ & 1 & & & & & & & & & & & & & & & \\
\hline $\begin{array}{l}\text { 3. Psychological Well- } \\
\text { Being }\end{array}$ & 4.63 & 1.31 & $-.41 * * *$ & $.69^{* * *}$ & 1 & & & & & & & & & & & & & & \\
\hline $\begin{array}{l}\text { 4. Sexuality }+ \text { Gender } \\
\text { Openness (All Contexts) }\end{array}$ & 4.51 & 1.59 & $-.22^{* * *}$ & $.38^{* * *}$ & $.34 * * *$ & 1 & & & & & & & & & & & & & \\
\hline $\begin{array}{l}\text { 5. Sexuality }+ \text { Gender } \\
\text { Openness (Parent) }\end{array}$ & 3.84 & 2.30 & $-.14 * *$ & $.24 * * *$ & $.23^{* * *}$ & $.74 * * *$ & 1 & & & & & & & & & & & & \\
\hline $\begin{array}{l}\text { 6. Sexuality }+ \text { Gender } \\
\text { Openness (Friends) }\end{array}$ & 5.68 & 1.68 & ז & $.25^{* * *}$ & $.20^{* * *}$ & $.76^{* * *}$ & $.40^{* * *}$ & 1 & & & & & & & & & & & \\
\hline $\begin{array}{l}\text { 7. Sexuality }+ \text { Gender } \\
\text { Openness (School) }\end{array}$ & 4.32 & 1.96 & $-.24 * * *$ & $.30^{* * *}$ & $.28^{* * *}$ & $.83^{* * *}$ & $.33^{* * *}$ & $.59^{* * *}$ & 1 & & & & & & & & & & \\
\hline $\begin{array}{l}\text { 8. Sexuality + Gender } \\
\text { Openness (Work) }\end{array}$ & 3.91 & 2.06 & $-.27^{* * *}$ & $.37 * * *$ & $.35^{* * *}$ & $.84 * * *$ & $.43^{* * *}$ & $.51 * * *$ & $.74 * * *$ & 1 & & & & & & & & & \\
\hline $\begin{array}{l}\text { 9. Anti-LGBTQ+ } \\
\text { Discrimination }\end{array}$ & 5.51 & 1.24 & $.63^{* * *}$ & $-.18^{* * *}$ & $-.25^{* * *}$ & $-.17 * *$ & $-.11 *$ & -.05 & $-.19^{* * *}$ & $-.22 * * *$ & 1 & & & & & & & & \\
\hline $\begin{array}{l}\text { 10. Personal Autonomy } \\
\text { Support (All Contexts) }\end{array}$ & 4.73 & 1.29 & $-.22^{* * *}$ & $.46^{* * *}$ & $.44 * * *$ & $.63^{* * *}$ & $.49^{* * *}$ & $.49^{* * *}$ & $.50^{* * *}$ & $.50^{* * * *}$ & $-.09 \nmid$ & 1 & & & & & & & \\
\hline $\begin{array}{l}\text { 11. Personal Autonomy } \\
\text { Support (Parent) }\end{array}$ & 4.20 & 1.98 & $-.15^{* *}$ & $.30^{* * *}$ & $.29^{* * *}$ & $.47^{* * *}$ & $.67 * * *$ & $.23^{* * *}$ & $.18 * *$ & $.23^{* * *}$ & -.06 & $.76 * * *$ & 1 & & & & & & \\
\hline $\begin{array}{l}\text { 12. Personal Autonomy } \\
\text { Support (Friend) }\end{array}$ & 5.67 & 1.36 & $-.10 *$ & $.35 * * *$ & $.30 * * *$ & $.46 * * *$ & $.26^{* * *}$ & $.61^{* * *}$ & $.32 * * *$ & $.29 * * *$ & .02 & $.76^{* * *}$ & $.44 * * *$ & 1 & & & & & \\
\hline $\begin{array}{l}\text { 13. Personal Autonomy } \\
\text { Support (School) }\end{array}$ & 4.42 & 1.54 & $-.22^{* * *}$ & $.37 * * *$ & $.38^{* * * *}$ & $.52^{* * *}$ & $.20^{* * *}$ & $.39^{* * *}$ & $.64 * * *$ & $.46^{* * * *}$ & -.05 & $.80^{* * *}$ & $.33^{* * *}$ & $.51 * * *$ & 1 & & & & \\
\hline $\begin{array}{l}\text { 14. Personal Autonomy } \\
\text { Support (Work) }\end{array}$ & 4.35 & 1.62 & $-.26^{* * *}$ & $.41^{* * *}$ & $.43^{* * *}$ & $.53^{* * *}$ & $.29^{* * *}$ & $.34 * * *$ & $.47^{* * *}$ & $.62^{* * *}$ & $-.18^{* *}$ & $.80^{* * *}$ & $.39^{* * *}$ & $.46^{* * *}$ & $.68^{* * *}$ & 1 & & & \\
\hline $\begin{array}{l}\text { 15. Group Identification } \\
\text { (Ingroup Affect) }\end{array}$ & 5.64 & 1.18 & .01 & $.24 * * *$ & $.18^{* * * *}$ & $.33^{* * *}$ & $.26^{* * *}$ & $.34 * * *$ & $.22^{* * *}$ & $.24 * * *$ & $.11 *$ & $.20^{* * *}$ & $.18^{* * *}$ & $.23^{* * *}$ & $.10 \nmid$ & .10 & 1 & & \\
\hline $\begin{array}{l}\text { 16. Group Identification } \\
\text { (Ingroup Member Ties) }\end{array}$ & 4.44 & 1.42 & .03 & $.12 *$ & .09 & $.20^{* * *}$ & $.15^{* *}$ & $.21 * * *$ & $.15^{*}$ & $.15^{* *}$ & $.11 *$ & $.18^{* * *}$ & $.14 * *$ & $.19^{* * *}$ & $.16^{* *}$ & $.10^{*}$ & $.45^{* * *}$ & 1 & \\
\hline $\begin{array}{l}\text { 17. Group Identification } \\
\text { (Ingroup Identity } \\
\text { Centrality) }\end{array}$ & 4.09 & 1.52 & $.20^{* * *}$ & $-.11 *$ & $-.10 *$ & .07 & ז.09. & $.12^{*}$ & -.02 & -.00 & $.22 * * *$ & -.04 & .01 & .03 & -.01 & $-.14 * *$ & $.39^{* * *}$ & $.57 * * *$ & 1 \\
\hline
\end{tabular}

Note. $\nmid p<.10, * \mathrm{p}<.05, * * \mathrm{p}<.01, * * * \mathrm{p}<.001$. Pairwise deletion was used for missing data. 
Table 6. Condition Means and Condition Effects for All Variables (Experiment 2).

\begin{tabular}{|c|c|c|c|c|c|}
\hline & \multicolumn{2}{|c|}{$\begin{array}{l}\text { Collective } \\
\text { Autonomy } \\
\text { Restriction } \\
\text { Condition }\end{array}$} & \multicolumn{2}{|c|}{$\begin{array}{l}\text { Collective } \\
\text { Autonomy Support } \\
\text { Condition }\end{array}$} & $\begin{array}{l}\text { Condition Effect } \\
\text { (ANOVA) }\end{array}$ \\
\hline $\begin{array}{l}\text { 1. Collective Autonomy } \\
\text { Restriction }\end{array}$ & 4.84 & 1.16 & 4.18 & 1.14 & $F(1,394)=33.22, p<.001, \eta_{2}=.08$ \\
\hline $\begin{array}{l}\text { 2. Personal Autonomous Need } \\
\text { Satisfaction }\end{array}$ & 4.23 & 1.30 & 5.06 & 1.15 & $F(1,394)=44.26, p<.001, \eta_{2}=.10$ \\
\hline 3. Psychological Well-Being & 4.18 & 1.31 & 5.05 & 1.15 & $F(1,394)=49.99, p<.001, \eta_{2}=.11$ \\
\hline $\begin{array}{l}\text { 4. Sexuality }+ \text { Gender } \\
\text { Openness (All Contexts) }\end{array}$ & 4.42 & 1.55 & 4.60 & 1.63 & $F(1,394)=1.33, p=.249, \eta_{2}=.003$ \\
\hline $\begin{array}{l}\text { 5. Sexuality }+ \text { Gender } \\
\text { Openness (Parent) }\end{array}$ & 3.91 & 2.30 & 3.78 & 2.30 & $F(1,394)=.30, p=.582, \eta_{2}=.001$ \\
\hline $\begin{array}{l}\text { 6. Sexuality }+ \text { Gender } \\
\text { Openness (Friends) }\end{array}$ & 5.56 & 1.69 & 5.80 & 1.67 & $F(1,394)=2.07, p=.152, \eta_{2}=.01$ \\
\hline $\begin{array}{l}\text { 7. Sexuality }+ \text { Gender } \\
\text { Openness (School) }\end{array}$ & 4.15 & 1.85 & 4.48 & 2.05 & $F(1,394)=2.44, p=.135, \eta_{2}=.01$ \\
\hline $\begin{array}{l}\text { 8. Sexuality + Gender } \\
\text { Openness (Work) }\end{array}$ & 3.75 & 2.02 & 4.07 & 2.09 & $F(1,394)=2.20, p=.139, \eta_{2}=.01$ \\
\hline $\begin{array}{l}\text { 9. Anti-LGBTQ+ } \\
\text { Discrimination }\end{array}$ & 5.67 & 1.26 & 5.36 & 1.21 & $F(1,394)=6.16, p=.014, \eta_{2}=.02$ \\
\hline $\begin{array}{l}\text { 10. Personal Autonomy } \\
\text { Support (All Contexts) }\end{array}$ & 4.65 & 1.25 & 4.80 & 1.32 & $F(1,394)=1.38, p=.242, \eta_{2}=.003$ \\
\hline $\begin{array}{l}\text { 11. Personal Autonomy } \\
\text { Support (Parent) }\end{array}$ & 4.13 & 1.97 & 4.26 & 1.99 & $F(1,378)=.41, p=.521, \eta_{2}=.001$ \\
\hline $\begin{array}{l}\text { 12. Personal Autonomy } \\
\text { Support (Friend) }\end{array}$ & 5.59 & 1.37 & 5.73 & 1.34 & $F(1,393)=1.07, p=.302, \eta_{2}=.003$ \\
\hline $\begin{array}{l}\text { 13. Personal Autonomy } \\
\text { Support (School) }\end{array}$ & 4.36 & 1.40 & 4.49 & 1.68 & $F(1,308)=.57, p=.450, \eta_{2}=.002$ \\
\hline $\begin{array}{l}\text { 14. Personal Autonomy } \\
\text { Support (Work) }\end{array}$ & 4.29 & 1.58 & 4.41 & 1.66 & $F(1,355)=.57, p=.451, \eta_{2}=.002$ \\
\hline
\end{tabular}




\section{Supplemental Analyses}

Free to fly the rainbow flag: The relation between collective autonomy and psychological well-being amongst LGBTQ+ individuals

Supplemental Table 1: Comparing the effects of experimental condition on key outcomes amongst LGBTQ+ individuals who did and did not identify as Trans or Genderqueer.

Supplemental Table 2: Results of a series of 2 (Condition) by 2 (sub-group identity) ANOVAs on all key outcomes.

Supplemental Table 3: Effect of condition on all key outcomes for Experiment 1a, Experiment 1b, and Experiment 2 when using more stringent exclusion criteria on the basis of participants' written responses.

Supplemental Table 4: Simple effects of P.6 condition on key outcomes amongst individuals who did and did not self-identify themselves on the basis of a superordinate LGBTQ+ identity.

Supplemental Table 5: Condition means, condition effect, and indirect effect (via autonomous need satisfaction) for each separate well-being outcome measured in Experiment 1b

Supplemental Table 6. Condition by group identification interaction effects when analyzing Experiment $1 \mathrm{a}$ and Experiment $1 \mathrm{~b}$ samples separately.

Supplemental Table 7: Condition means, condition effect, and indirect effect (via autonomous need satisfaction) for each separate well-being outcome measured in Experiment 2 
Supplemental Table 1a: Comparing the effects of experimental condition on key outcomes amongst LGBTQ+ individuals who did and did not identify as Trans or Genderqueer (Merged Data from Experiment 1a and Experiment 1b)

\begin{tabular}{llll}
\hline & $\begin{array}{l}\text { Restriction } \\
\text { Condition } \\
M(S D)\end{array}$ & $\begin{array}{l}\text { Support } \\
\text { Condition } \\
M(S D)\end{array}$ & Effect \\
\hline $\begin{array}{l}\text { LGBTQ+ individuals who } \\
\text { did } \text { not } \text { identify as Trans or }\end{array}$ & & & \\
$\begin{array}{l}\text { Gender Queer }(\mathrm{N}=408) \\
\text { Collective Autonomy } \\
\text { Restriction }\end{array}$ & $.24(.95)$ & $-.33(1.00)$ & $F(1,406)=34.71, p<.001 \delta_{2}=.08$ \\
$\begin{array}{l}\text { Personal Autonomous } \\
\text { Need Satisfaction }\end{array}$ & $-.27(.98)$ & $.41(93)$ & $F(1,407)=52.37, p<.001 \delta_{2}=.11$ \\
$\quad \begin{array}{l}\text { Psych. Wellbeing } \\
\text { LGBTQ+ individuals who }\end{array}$ & $-.28(.94)$ & $.47(.87)$ & $F(1,407)=70.52, p<.001 \delta_{2}=.15$ \\
$\begin{array}{l}\text { identified as Trans or Gender } \\
\text { Queer (N=75) }\end{array}$ & & & \\
$\begin{array}{l}\text { Collective Autonomy } \\
\text { Restriction }\end{array}$ & $.30(.80)$ & $.14(.93)$ & $F(1,73)=.64, p=.427, \delta_{2}=.01$ \\
$\begin{array}{l}\text { Personal Autonomous } \\
\text { Need Satisfaction }\end{array}$ & $-.49(.85)$ & $-.15(.83)$ & $F(1,73)=3.03, p=.086, \delta_{2}=.04$ \\
$\begin{array}{l}\text { Psychological } \\
\text { Wellbeing }\end{array}$ & $-.78(.90)$ & $-.13(.89)$ & $F(1,73)=9.82, p=.002, \delta_{2}=.12$ \\
\hline
\end{tabular}


Supplemental Table 1b: Comparing the effects of experimental condition on key outcomes amongst LGBTQ+ individuals who did and did not identify as Trans or Genderqueer. (Experiment 2)

\begin{tabular}{|c|c|c|c|}
\hline & $\begin{array}{l}\text { Restriction } \\
\text { Condition } \\
M(S D)\end{array}$ & $\begin{array}{l}\text { Support } \\
\text { Condition } \\
M(S D)\end{array}$ & $\begin{array}{l}\text { Effect } \\
F, p, \text { eta } 2\end{array}$ \\
\hline \multicolumn{4}{|l|}{$\begin{array}{l}\text { LGBTQ+ individuals who } \\
\text { did not identify as Trans or } \\
\text { Gender Queer }(\mathrm{N}=354)\end{array}$} \\
\hline $\begin{array}{l}\text { Collective Autonomy } \\
\text { Restriction }\end{array}$ & $4.84(1.15)$ & $4.15(1.17)$ & $F(1,352)=32.51, p<.001 \delta_{2}=.09$ \\
\hline $\begin{array}{l}\text { Personal Autonomous } \\
\text { Need Satisfaction }\end{array}$ & $4.33(1.28)$ & $5.08(1.15)$ & $F(1,352)=33.89, p<.001 \delta_{2}=.09$ \\
\hline Psych. Wellbeing & $4.28(1.30)$ & $5.11(1.17)$ & $F(1,352)=39.94, p<.001 \delta_{2}=.10$ \\
\hline \multicolumn{4}{|l|}{$\begin{array}{l}\text { LGBTQ+ individuals who } \\
\text { identified as Trans or Gender } \\
\text { Queer }(\mathrm{N}=42)\end{array}$} \\
\hline $\begin{array}{l}\text { Collective Autonomy } \\
\text { Restriction }\end{array}$ & $4.79(1.24)$ & $4.47(.76)$ & $F(1,40)=.93, p=.341, \delta_{2}=.02$ \\
\hline $\begin{array}{l}\text { Personal Autonomous } \\
\text { Need Satisfaction }\end{array}$ & $3.55(1.29)$ & $4.82(1.13)$ & $F(1,40)=11.20, p=002, \delta_{2}=.22$ \\
\hline $\begin{array}{l}\text { Psychological } \\
\text { Wellbeing }\end{array}$ & $3.40(1.17)$ & $4.49(.77)$ & $F(1,40)=12.07, p=.001, \delta_{2}=.23$ \\
\hline
\end{tabular}


Supplemental Table 2a: Results of a series of 2 (Condition: Restriction vs. Support) by 2 (Subgroup Identity: Trans or Genderqueer LGBTQ+ Individuals vs. Non-Trans or Genderqueer LGBTQ+ individuals) ANOVAs on all key outcomes (Experiment 1a and Experiment $1 \mathrm{~b}$ merged data).

\begin{tabular}{|c|c|c|c|}
\hline & Condition & Sub-Group Identity & Interaction Effect \\
\hline $\begin{array}{l}\text { Collective } \\
\text { Autonomy } \\
\text { Restriction }\end{array}$ & $\begin{array}{l}F(1,479)=9.08, p=.003 \\
\delta_{2}=.02\end{array}$ & $\begin{array}{l}F(1,479)=4.96, p=.026, \\
\delta_{2}=.01\end{array}$ & $\begin{array}{l}F(1,479)=2.87, p=.091, \\
\delta_{2}=.01\end{array}$ \\
\hline $\begin{array}{l}\text { Personal } \\
\text { Autonomous } \\
\text { Need } \\
\text { Satisfaction }\end{array}$ & $\begin{array}{l}F(1,480)=18.68, p<.001 \\
\delta_{2}=.04\end{array}$ & $\begin{array}{l}F(1,480)=11.10, p<.001 \\
\delta_{2}=.02\end{array}$ & $\begin{array}{l}F(1,480)=2.12, p=.146, \\
\delta_{2}=.004\end{array}$ \\
\hline $\begin{array}{l}\text { Psychological } \\
\text { Wellbeing }\end{array}$ & $\begin{array}{l}F(1,480)=37.81, p<.001 \\
\delta_{2}=.07\end{array}$ & $\begin{array}{l}F(1,480)=23.07, p<.001 \\
\delta_{2}=.07\end{array}$ & $\begin{array}{l}F(1,480)=.21, p=.650 \\
\delta_{2}=.001\end{array}$ \\
\hline
\end{tabular}

Supplemental Table 2b: Results of a series of 2 (Condition: Restriction vs. Support) by 2 (Subgroup Identity: Trans or Genderqueer LGBTQ+ Individuals vs. Non-Trans or Genderqueer LGBTQ+ individuals) ANOVAs on all key outcomes (Experiment 2).

\begin{tabular}{|c|c|c|c|}
\hline & Condition & Sub-Group Identity & Interaction Effect \\
\hline $\begin{array}{l}\text { Collective } \\
\text { Autonomy } \\
\text { Restriction }\end{array}$ & $\begin{array}{l}F(1,392)=7.31, p= \\
.007, \delta_{2}=.018\end{array}$ & $\begin{array}{l}F(1,392)=.50 p=.479 \\
\delta_{2}=.00\end{array}$ & $\begin{array}{l}F(1,392)=1.06, p=.303, \\
\delta_{2}=.002\end{array}$ \\
\hline Personal & $F(1,392)=25.65, p<$ & $F(1,392)=6.83, p=$ & $F(1,392)=1.66, p=.199$ \\
\hline $\begin{array}{l}\text { Autonomous } \\
\text { Need } \\
\text { Satisfaction }\end{array}$ & $.001, \delta_{2}=.06$ & $.009, \delta_{2}=.02$ & $\delta_{2}=.004$ \\
\hline $\begin{array}{l}\text { Psychological } \\
\text { Wellbeing }\end{array}$ & $\begin{array}{l}F(1,392)=23.38, p< \\
.001, \delta_{2}=.06\end{array}$ & $\begin{array}{l}F(1,392)=14.17, p< \\
.001, \delta_{2}=.04\end{array}$ & $\begin{array}{l}F(1,392)=.44, p=.507 \\
\delta_{2}=.001\end{array}$ \\
\hline
\end{tabular}


Supplemental Table 3: Effect of condition on all key outcomes for Experiment 1a, and Experiment 1b, and Experiment 2 when using more stringent exclusion criteria on the basis of participants' written responses.

\begin{tabular}{llll}
\hline & $\begin{array}{l}\text { Collective } \\
\text { Autonomy }\end{array}$ & Personal Autonomy & $\begin{array}{l}\text { Psychological Well- } \\
\text { Being }\end{array}$ \\
\hline $\begin{array}{l}\text { Experiment 1a }(\mathrm{N}= \\
\text { 97 after exclusions })\end{array}$ & $\begin{array}{l}F(1,95)=21.81, \\
p<.001, \delta 2=.19\end{array}$ & $\begin{array}{l}F(1,95)=14.60, \\
p<.001, \delta 2=.13\end{array}$ & $\begin{array}{l}\mathrm{F}(1,95)=.45, \\
p=.506, \delta 2=.01\end{array}$ \\
Experiment $1 \mathrm{~b}(\mathrm{~N}=$ & $F(1,264)=36.82$, & $F(1,263)=69.70$, & $\mathrm{F}(1,263)=177.22$, \\
265 after exclusions) & $p<.001, \delta 2=.12$ & $p<.001, \delta 2=.21$ & $p<.001, \delta 2=.40$ \\
Experiment 2 $(\mathrm{N}=$ & $F(1,341)=41.47$, & $F(1,341)=46.64$, & $\mathrm{F}(1,341)=58.96$, \\
341 after exclusions) & $p<.001, \delta 2=.11$ & $p<.001, \delta_{2}=.12$ & $p<.001, \delta_{2}=.15$ \\
\hline
\end{tabular}

Note: Our more stringent exclusion criteria excluded people who: wrote that they could not think of, or articulate a response; wrote about the opposite type of experience as what was asked (i.e., they gave an example of collective autonomy support if in the restriction condition, or an example of restriction in support) or wrote about topics that were related to their community but not collective autonomy restriction. 
Supplemental Table 4: Simple effects of condition on key outcomes amongst individuals who did and did not self-identify themselves on the basis of a superordinate LGBTQ+ identity.

Condition by Superordinate Did NOT select superordinate group when Did select superordinate group when

LGBTQ+ Identity Interaction describing identification to LGBTQ+ community community

$\mathrm{b}(95 \% \mathrm{CI})$ $\mathrm{b}(95 \% \mathrm{CI})$ $\mathrm{b}(95 \% \mathrm{CI})$

\begin{tabular}{|c|c|c|c|}
\hline & $0(95 \%(1)$ & $\mathrm{D}(95 \% \mathrm{C}(1)$ & $\mathrm{b}(93 \%(1)$ \\
\hline Experiment 1a & & & \\
\hline $\begin{array}{l}\text { Collective } \\
\text { autonomy } \\
\text { restriction }\end{array}$ & $.49(-.41,1.40)$ & $-1.11(-1.80, .43)^{* *}$ & $-.62(-1.22,-.02)^{*}$ \\
\hline $\begin{array}{l}\text { Personal } \\
\text { Autonomous } \\
\text { need } \\
\text { satisfaction }\end{array}$ & $-.27(-1.21, .67)$ & $.97(.27,1.69)^{* *}$ & $.71(.09,1.32)^{*}$ \\
\hline $\begin{array}{l}\text { Psychological } \\
\text { well-being }\end{array}$ & $.36(-.68,1.35)$ & $-.08(-.85, .68)$ & $.25(-.41, .92)$ \\
\hline Experiment 1b & & & \\
\hline $\begin{array}{l}\text { Collective } \\
\text { autonomy } \\
\text { restriction }\end{array}$ & $-.47(-.99, .05) \nmid$ &.$-.39(-.76,-.02)^{*}$ & $-.87(-1.23,-.50)^{* * *}$ \\
\hline $\begin{array}{l}\text { Personal } \\
\text { Autonomous } \\
\text { need } \\
\text { satisfaction }\end{array}$ & $.60(.06,1.14)^{*}$ & $.59(.20, .97)^{* *}$ & $1.19(.80,1.57)^{* * *}$ \\
\hline $\begin{array}{l}\text { Psychological } \\
\text { well-being }\end{array}$ & $.64(.07,1.21)^{*}$ & $1.21(.80,1.61)^{* * *}$ & $1.85(1.46,2.25)^{* * *}$ \\
\hline Experiment 2 & & & \\
\hline $\begin{array}{l}\text { Collective } \\
\text { autonomy } \\
\text { restriction }\end{array}$ & $-.21(-.67, .25)$ & $-.54(-.90,-.19)^{* *}$ & $-.75(-1.05,-.46)^{* * *}$ \\
\hline $\begin{array}{l}\text { Personal } \\
\text { Autonomous } \\
\text { need } \\
\text { satisfaction }\end{array}$ & $-.16(-.66, .33)$ & $.91(.53,1.29)^{* * *}$ & $.75(.44,1.07)^{* * *}$ \\
\hline $\begin{array}{l}\text { Psychological } \\
\text { well-being }\end{array}$ & $-.15(-.64, .35)$ & $.97(.59,1.35)^{* * *}$ & $.82(.51,1.14)^{* * *}$ \\
\hline
\end{tabular}

Note: We regressed each outcome onto condition, identification with a superordinate LGBTQ+ community (yes / no), and the interaction. The $b$ coefficients reflect non-standardized coefficients. Condition was dummy coded $0=$ collective autonomy restriction; $1=$ collective autonomy support). Superordinate LGBTQ community identification was dummy coded $0=$ no; $1=$ yes

$\nmid p<.10, * p=.05, * * p=.01, * * * p=.001$ 
Supplemental Table 5: Condition means, condition effect, and indirect effect (via autonomous need satisfaction) for each separate well-being outcome measured in Experiment 1b.

\begin{tabular}{|c|c|c|c|c|c|c|}
\hline & \multicolumn{2}{|c|}{$\begin{array}{l}\text { Collective } \\
\text { Autonomy } \\
\text { Restriction } \\
\text { Condition }\end{array}$} & \multicolumn{2}{|c|}{$\begin{array}{l}\text { Collective } \\
\text { Autonomy } \\
\text { Support } \\
\text { Condition }\end{array}$} & \multirow[t]{2}{*}{$\begin{array}{l}\text { Total Condition Effect } \\
\text { (ANOVA) }\end{array}$} & \multirow[t]{2}{*}{$\begin{array}{l}\text { Indirect Condition } \\
\text { Effect Through } \\
\text { Personal Autonomy } \\
\text { (PROCESS) }\end{array}$} \\
\hline & $\mathrm{M}$ & SD & $\mathrm{M}$ & $\mathrm{SD}$ & & \\
\hline 1. Life Satisfaction & 3.59 & 1.58 & 4.61 & 1.52 & $F(1,367)=40.08, p<.001, \eta_{2}=.10$ & $.54[.24, .84]$ \\
\hline 2. Self-Esteem & 4.05 & 1.69 & 5.41 & 1.36 & $F(1,367)=71.73, p<.001, \eta_{2}=.16$ & $.60[.40, .81]$ \\
\hline 3. Depression & 4.44 & 1.84 & 2.81 & 1.82 & $F(1,367)=73.09, p<.001, \eta_{2}=.17$ & $-.72[-.96,-.49]$ \\
\hline 4. Anger & 4.51 & 1.86 & 2.35 & 1.61 & $F(1,368)=141.84, p<.001, \eta_{2}=.28$ & $-.54[-.73,-.36]$ \\
\hline 5. Anxious & 4.31 & 1.80 & 2.79 & 1.73 & $F(1,367)=67.50, p<.001, \eta_{2}=.16$ & $-.63[-.85,-.43]$ \\
\hline
\end{tabular}


Supplemental Table 6. Condition by group identification interaction effects when analyzing Experiment 1a and Experiment $1 \mathrm{~b}$ samples separately.

\begin{tabular}{clll}
\hline & $\begin{array}{l}\text { Condition by Ingroup } \\
\text { Affect Interaction } \\
\mathrm{b}(95 \% \mathrm{CI})\end{array}$ & $\begin{array}{l}\text { Condition by Ingroup } \\
\text { Ties Interaction } \\
\mathrm{b}(95 \% \mathrm{CI})\end{array}$ & $\begin{array}{l}\text { Condition by Ingroup } \\
\text { Centrality Interaction } \\
\mathrm{b}(95 \% \mathrm{CI})\end{array}$ \\
\hline $\begin{array}{c}\text { Experiment 1a } \\
\begin{array}{l}\text { Personal } \\
\text { Autonomous } \\
\text { need } \\
\text { satisfaction }\end{array}\end{array}$ & $.19(-.19,57)$ & $-.06(-.45, .32)$ & $-.02(-.38, .34)$ \\
$\begin{array}{l}\text { Psychological } \\
\text { well-being }\end{array}$ & $.08(-.34, .50)$ & $-.21(-.64, .23)$ & $.08(-.32, .48)$ \\
$\begin{array}{c}\text { Experiment 1b } \\
\text { Personal } \\
\begin{array}{l}\text { Autonomous } \\
\text { need } \\
\text { satisfaction } \\
\text { Psychological } \\
\text { well-being }\end{array}\end{array}$ & $.25(-.009, .50)+$ & $-.03(-.21, .15)$ & $.03(-.16, .22)$ \\
\hline
\end{tabular}

Note. We entered all three two-way condition by GID sub-factor interactions into the model simultaneously. All continuous predictor variables were mean centered and condition was contrast coded (i.e., $-.5=$ collective autonomy restriction and $.5=$ collective autonomy support) for this analysis. $\ngtr p<.10,{ }^{*} p=.05,{ }^{*} p=.01, * * * p=.001$ 
Supplemental Table 7: Condition means, condition effect, and indirect effect (via autonomous need satisfaction) for each separate well-being outcome measured in Experiment 2.

\begin{tabular}{|c|c|c|c|c|c|c|}
\hline & \multicolumn{2}{|c|}{$\begin{array}{l}\text { Collective } \\
\text { Autonomy } \\
\text { Restriction } \\
\text { Condition }\end{array}$} & \multicolumn{2}{|c|}{$\begin{array}{l}\text { Collective } \\
\text { Autonomy } \\
\text { Support } \\
\text { Condition }\end{array}$} & \multirow[t]{2}{*}{$\begin{array}{l}\text { Total Condition Effect } \\
\text { (ANOVA) }\end{array}$} & \multirow{2}{*}{$\begin{array}{c}\text { Indirect Condition } \\
\text { Effect Through } \\
\text { Personal } \\
\text { Autonomous Need } \\
\text { Satisfaction } \\
\text { (PROCESS) }\end{array}$} \\
\hline & M & SD & M & $\mathrm{SD}$ & & \\
\hline 1. Life Satisfaction & 3.81 & 1.57 & 4.13 & 1.49 & $F(1,394)=4.23, p=.040, \eta_{2}=.01$ & $.53[.35, .72]$ \\
\hline 2. Self-Esteem & 4.50 & 1.48 & 4.95 & 1.39 & $F(1,394)=9.97, p=.002, \eta_{2}=.03$ & $.52[.35, .70]$ \\
\hline 3. Depression & 3.91 & 1.70 & 2.97 & 1.58 & $F(1,394)=33.02, p<.001, \eta_{2}=.08$ & $-.62[-.82,-.43]$ \\
\hline 4. Anger & 3.70 & 1.66 & 2.23 & 1.42 & $F(1,394)=89.49, p<.001, \eta_{2}=.19$ & $-.46[-.65,-.30]$ \\
\hline 5. Anxious & 3.81 & 1.71 & 2.62 & 1.46 & $F(1,394)=55.99, p<.001, \eta_{2}=.12$ & $-.55[-.75,-.37]$ \\
\hline
\end{tabular}


Free to fly the rainbow flag: The relation between collective autonomy and psychological well-being amongst LGBTQ+ individuals

\section{Supplemental Materials}

EXPERIMENT 1a....................................................................2

Experimental Manipulation.................................................2

Question of Focus in Present Research........................................................

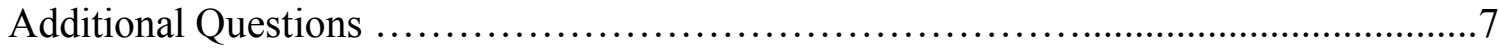

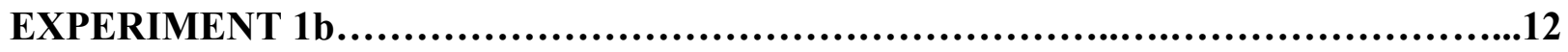

Experimental Manipulation................................................ 12

Question of Focus in Present Research ................................................13

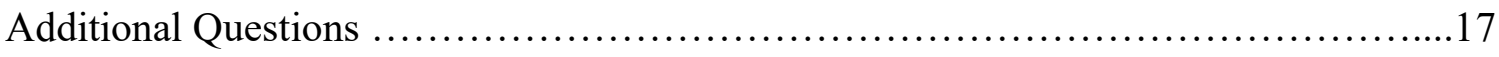

EXPERIMENT 2 ........................................................................21

Experimental Manipulation...................................................21

Question of Focus in Present Research ..................................................22

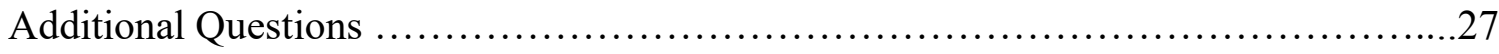

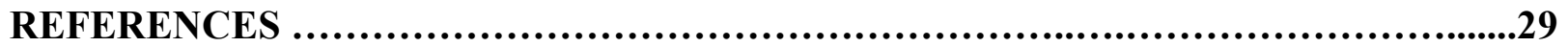




\section{Experiment 1a-Materials}

\section{Collective Autonomy Support vs. Restriction Manipulation}

\section{SEEN BY EVERYONE}

We would now like you to engage in a brief written reflection activity. In this activity we want you think about and write about your LGBTQ+ community, and more specifically, about the collective autonomy of your LGBTQ+ community. Before you begin, please read a little more about what we mean by the term "collective autonomy".

What is Collective Autonomy? Collective autonomy refers to your subjective perception that your group - in this case your LGBTQ+ community - can determine its own group identity and act in accordance with its group identity. In other words, collective autonomy means that you, as a people, have determined what makes you who you are as a group, and that you and your community feel free and welcome in society to act in ways that reflect your group identity. Several different social contexts (actions of other groups, attitudes of mainstream society, political and legal decisions, etc.,) might lead you and your group to feel either a lack of collective autonomy OR a strong sense of collective autonomy.

\section{A. SEEN BY COLLECTIVE AUTONOMY SUPPORT CONDITION ONLY}

In this task, we would like you to reflect about a time when you felt your group's collective autonomy was SUPPORTED... Here we will ask you to think about your own experiences as part of the LGBTQ+ community. We want to know about a time you can recall when you felt that your community had collective autonomy in one way or another. You may perceive a strong sense of collective autonomy when your group benefits from open societal processes that allow your group to freely define who you are as a people, or processes that support your group's right to your own customs and values and respect your right to act in ways that reflect who you are as a people. For example: you might think of a specific event that you feel had a supportive impact on the LGBTQ+ community (e.g., marriage equality laws passed in U.S., more exposure for trans people in media - tv shows, tours, etc.,).

Please take a moment now to think about and reflect on a time in which you felt and recognized that your group $H A D$ collective autonomy in at least one way or another. This is a free-flowing reflection activity. There is no right or wrong way to describe whatever event or time you're reflecting on. As this is meant to be a brief reflection activity, we suggest spending no more than 5 minutes. 


\section{B. SEEN BY COLLECTIVE AUTONOMY RESTRICTION CONDITION ONLY}

In this task we would like you to reflect about a time when you felt your group's collective autonomy was THREATENED... Here we will ask you to think about your own experiences as part of the $L G B T Q+$ community. We want to know about a time you can recall when you felt that your community did not have collective autonomy in one way or another. You may perceive a lack of collective autonomy when your group is affected by controlling societal processes that prevent your group from freely defining who you are as a people, or processes that impose customs or values on your group, or restrict you from acting in ways that reflect who you are as a people. For example: you might think about an event that you feel had a threatening impact on the $L G B T Q+$ community (e.g., prohibition of $L G B T Q+$ people/messages in Russia, lack of support for gender neutral spaces - washrooms, children's clothes/toy sections, etc.,).

Please take a moment now to think about and reflect on a time in which you felt your group did NOT have collective autonomy in at least one way or another. This is a freeflowing reflection activity and there is no right or wrong way to describe whatever event or time you're reflecting on. As this is meant to be a brief reflection activity, we suggest that you spend no more than 5 minutes.

\section{Measures Reported in Experiment 1a of Present Manuscript}

\section{Sub-group identification amongst the LGBTQ+ community (Items developed by authors)}

Which group(s) do you feel most strongly connected to? Please choose all groups that apply.

The Trans community (e.g., those connecting based on their marginalized gender identities people who may identify as transgender, transsexual, non-binary, genderqueer, etc.,)

The Gay and Lesbian community (e.g., those connecting based on their marginalized sexual orientations - people who may identify as gay, lesbian, bisexual, asexual, pansexual, etc.,)

a The LGBTQ+ community as a whole (e.g., those connecting based on the myriad diverse identities represented by the overall community)

Another group or community based on gender and sexual identity not described above (please specify):

I I identify as either non-heterosexual and/or non-cisgender, but do not connect as much with any "community" based on gender and/or sexual identity 


\section{Group Identification Scale (Cameron, 2004):}

We would like you to answer some questions about your gender and sexual identity that you identified in Part 1. There are no right or wrong answers. Please use the 7-point scale to indicate the extent to which you agree with each of these statements.

1. I feel strong ties to other LGBTQ+ community members.

2. I don't feel a sense of being "connected" with other members of the LGBTQ+ community.

3. Overall, being LGBTQ+ has very little to do with how I feel about myself.

4. In general, being LGBTQ+ is an important part of my self-image.

5. In general, I am glad to be LGBTQ+.

6. I don't feel good about being LGBTQ+.

\section{Collective Autonomy Restriction (Adapted from Kachanoff, Taylor, Caouette, Khullar, \& Wohl, 2018)}

Please rate your agreement with the following statements regarding whether your LGBTQ+ community has either been free to develop and practice its own culture in society or has been controlled and prevented from doing so by other groups.

Please respond to these items IN RELATION TO THE EVENT OR TIME YOU DESCRIBED IN THE LAST SECTION:

1. My LGBTQ+ community felt free to determine who we are as a people (reversed scored).

2. My LGBTQ+ community did NOT always feel free to determine our own group identity: our customs, practices, values, beliefs, traditions.

3. My LGBTQ+ community felt free to behave in ways that reflected our community's values and shared beliefs openly in society (reversed scored).

4. My LGBTQ+ community did NOT feel free to express our identities and practice our traditions openly in society.

5. Other groups tried to prevent my LGBTQ + community from practicing our cultural practices and customs openly in society

6. Other groups tried to control what my LGBTQ+ community should value and believe.

7. Other groups did NOT try to prevent my LGBTQ+ community from expressing our identities and practicing our traditions openly in society (reversed scored).

8. Other groups did NOT try to prevent my LGBTQ+ community from behaving in ways that reflect our community's values and shared beliefs (reversed scored).

\section{Personal Autonomy Need Satisfaction (Sheldon \& Gunz, 2009):}

Please rate your agreement with the following statements bearing in mind your feelings IN RELATION TO THE EVENT OR TIME YOU DESCRIBED IN THE LAST SECTION: 
1. There were people telling me what I had to do.

2. I was free to do things in my own way.

3. I had a lot of pressures I could do without.

4. My choices expressed my "true self"

5. I had to do things against my will.

6. I was really doing what interests me.

\section{Psychological Wellbeing Scale (Life Satisfaction; Diener et al., 1985)}

Please rate your agreement with the following statements (on a 7-point scale) based on how you feel IN RELATION TO THE TIME OR EVENT YOU DESCRIBED IN THE LAST SECTION.

1. In most ways my life is close to my ideal.

2. The conditions of my life are excellent.

3. I am satisfied with my life.

4. So far I have gotten important things I want in life.

5. If I could live my life over, I would change almost nothing.

\section{Perceived Anti-LGBTQ+ Discrimination (Kachanoff et al., 2018)}

Please rate your agreement with the following questions based on how you feel IN RELATION TO THE TIME OR EVENT YOU DESCRIBED IN THE LAST SECTION.

1. It was common that members from other groups discriminated against members of my group.

2. My community was the target of prejudice

3. It was rare that members of my community faced discrimination. 
Personal Autonomy Support from Parental Figures (Weinstein, Ryan, DeHaan, Przybylski, Legate, \& Ryan, 2012)

For the next two questions below, we will ask you to identify people that best represent parental figures - someone who has had a significant role in raising or caring for you (e.g., "mother", "father", "guardian", "older sibling", "close friend", etc.,). We will ask you to rate 3 statements for each person you identify (e.g., once for the first person you identify and once more for the second person you identify).

Please fill in the blank for each statement with someone that best represents a parental figure and then rate your agreement to each statement.

1. I feel free to be who I am when I am with my:

2. I have a say in what happens and can voice my opinion when I am with my:

3. I feel controlled and pressured to be certain ways when I am with my:

*Participants were asked to repeat these three questions with another parental figure.

Personal Autonomy Support from Other LGBTQ+ Community Members (Used in Footnote 2 of Present Manuscript; Adapted from Legate, Ryan, \& Rogge, 2017)

Please rate your agreement with each of the statements below based on your feelings about the LGBTQ+ community.

1. I feel that the people from my community, with whom I interact on a regular basis, provide me with choices and options during our interactions

2. I feel that the people from my community, with whom I interact on a regular basis, understand me.

3. I feel that the people from my community, with whom I interact on a regular basis, are able to be open with me.

4. I feel that the people from my community with, whom I interact on a regular basis, accept me as a person. 


\title{
Additional Measures from Experiment 1a Beyond the Scope of the Present Manuscript
}

\author{
Measure of Writing Prime Event Importance (Items developed by authors):
}

Please respond, using a 7-point scale, your feelings about the following questions IN RELATION TO THE TIME OR EVENT YOU DESCRIBED IN THE LAST SECTION:

1. How important do you feel the event/time you reflected upon is for the subcommunity/ies within the broader LGBTQ+ group that you identified at the beginning of the study?

2. How important do you feel this event/time is for you personally?

3. When thinking about the collective autonomy of your LGBTQ+ community TODAY, would you say that overall your group has more, less, or the same amount of collective autonomy as during the event/time you described?

Group Agency (Adapted from Shnabel \& Nadler, 2008):

Please rate your agreement with the following statements (on a 7-point scale) based on how you feel IN RELATION TO THE TIME OR EVENT YOU DESCRIBED IN THE LAST SECTION.

1. In relation to the event/time, I would say that my LGBTQ+ community has a lot of control as a group.

2. In relation to the event/time, I would say that my LGBTQ + community has a lot of power as a group.

Desire for Group Power (Adapted from Shnabel \& Nadler, 2008):

Please rate your agreement with the following statements (on a 7-point scale) based on how you feel IN RELATION TO THE TIME OR EVENT YOU DESCRIBED IN THE LAST SECTION.

1. In relation to the event/time my LGBTQ+ community would like to have a greater level of control over the interactions between ourselves and mainstream and traditional groups.

2. In relation to the event/time my LGBTQ+ community would like to have more of a say during our interactions with mainstream and traditional groups.

3. In relation to the event/time, my LGBTQ + community would like to have more power as a group. 
Group Entitativity Scale (Hogg et al., 2007):

Please rate your agreement with the following questions based on how you feel IN RELATION TO THE TIME OR EVENT YOU DESCRIBED IN THE LAST SECTION.

1. How cohesive is the LGBTQ+ community as a group?

2. How important is the LGBTQ+ community to its members?

3. Overall, how similar are members of the LGBTQ+ community to each other?

4. Some groups are coherent; their attitudes, values, and goals seem to be harmonious and compatible. Other group's attitudes, values, and goals seem to be incompatible or in disagreement. How coherent is the LGBTQ+ community?

5. Some groups have the characteristic of being distinctive or unique. That is, they do not share many qualities or characteristics with other groups. How distinctive is the LGBTQ+ community?

\section{Outgroup Attitudes}

Feeling Thermometer (Haddock, Zanna, \& Esses, 1993):

1. Thinking about the time/event you reflected upon, how warm do your feel towards other members of the LGBTQ+ community?

2. Thinking about the time/event you reflected upon, how warm do your feel towards members of other groups NOT affiliated with the LGBTQ+ community? (e.g., the mainstream and/or traditional population).

\section{Trait ratings (Crocker \& Luhtanen, 1990):}

Please rate each of the words below based on your feelings towards the mainstream and/or traditional (i.e., non-LGBTQ+) population IN RELATION TO THE TIME OR EVENT YOU DESCRIBED IN THE LAST SECTION. (e.g., overall, how much do you feel that the mainstream or traditional population is rude?):

1. Rude

2. Self-Centered

3. Insensitive

4. Motivated

5. Considerate

6. Ambitious

7. Creative

8. Friendly

9. Sincere

10. Trustworthy

\section{Collective Action (Items developed by authors):}

Although you may have already done some of the actions listed below, please rate your agreement with the following statements based on what you feel you would do in the future: 
1. I would go out of my way to collect information on LGBTQ+ issues.

2. I would correct other's use of homophobic and transphobic language.

3. I would lobby my members of parliament regarding LGBTQ+ issues.

4. I would volunteer for or donate money to LGBTQ+ organizations or events aimed at LGBTQ+ issues.

5. I would participate in protests regarding $\mathrm{LBGTQ}+$ issues.

\section{Collective Angst (Wohl \& Branscombe, 2010):}

Although you may have already done some of the actions listed below, please rate your agreement with the following statements based on what you feel you would do in the future:

1. I would go out of my way to collect information on LGBTQ+ issues.

2. I would correct other's use of homophobic and transphobic language.

3. I would lobby my members of parliament regarding LGBTQ+ issues.

4. I would volunteer for or donate money to LGBTQ+ organizations or events aimed at LGBTQ+ issues.

5. I would participate in protests regarding LBGTQ+ issues.

\section{Personal Regulatory Style for Acting in Accord With LGBTQ+ Identity (Chirkov et al., 2003):}

We would now like to know why you might choose to follow and endorse the different CUSTOMS, PRACTICES and VALUES that you feel come from your LGBTQ+ community. Please rate your agreement with each of the statements below concerning the different reasons that you might choose to endorse the values of your community.

1. Because of external pressures (to get rewards or avoid punishments). I follow the customs, practices and values of my community either because people insist on me doing so, I expect to get some kind of reward, or in order to avoid some punishment.

2. To get approval or avoid guilt. I follow the customs, practices and values of my community either because people around me would approve of me for doing so, because I think I should, or because if I didn't I might feel guilty, ashamed, or anxious.

3. Because it is important. I follow the customs, practices and values of my community because I personally believe that it is important and worthwhile to behave this way.

4. Because I have thoughtfully considered and fully chosen to do so. I have thought about the customs, practices and values of my community and have considered alternatives. It makes good sense to me to act this way, I feel free in doing so, and I feel responsible for the outcomes. 


\section{Open Ended Identification of Sexual/Gender Identity (Item created by authors):}

Please describe how you most strongly identify in terms of your sexual and gender identity (e.g., some individuals may describe themselves as follows: "I identify as a cisgender lesbian woman" or "I identify as a queer trans man", or "I identify as a trans woman" etc.,). Please use any terms that fit with your own feelings around identity and expression.

\section{Identification with different flags of the LGBTQ+ community (Items created by authors):}

Participants rated from 0 to 100 how much they identified with the following flags

- Bisexual Flag

- Gender Queer Flag

- Pansexual Flag

- Drag Queen/ King Flag

- Gay Q LGBTQ Flag

- Lesbian Flag

- Trans Flag

- Asexual Flag

\section{Other Demographics}

1. Do you identify as an ethnic or cultural minority? If "yes", what ethnic or cultural minority do you identify with?

1. Yes

2. No

2. What is your mother tongue (i.e., first language)?

3. Please estimate your weekly personal income, before taxes.

\begin{tabular}{|c|c|c|c|c|c|c|c|c|c|}
\hline $\begin{array}{l}\text { More } \\
\text { than } \\
\$ 2,500\end{array}$ & $\begin{array}{c}\$ 2,000- \\
\$ 2,500\end{array}$ & $\begin{array}{c}\$ 1,500- \\
\$ 2,000\end{array}$ & $\begin{array}{l}\$ 1,500- \\
\$ 2,000\end{array}$ & $\begin{array}{c}\$ 1,250- \\
\$ 1,500\end{array}$ & $\begin{array}{c}\$ 1,000- \\
\$ 1,250\end{array}$ & $\begin{array}{l}\$ 750- \\
\$ 1,000\end{array}$ & $\begin{array}{l}\$ 500- \\
\$ 750\end{array}$ & $\begin{array}{c}\$ 250- \\
500\end{array}$ & $\begin{array}{c}\$ 250 \text { or } \\
\text { less }\end{array}$ \\
\hline 1 & 2 & 3 & 4 & 5 & 6 & 7 & 8 & 9 & 10 \\
\hline
\end{tabular}


4. How would you rate your socioeconomic class?

\begin{tabular}{|c|c|c|c|c|}
\hline Upper Class & $\begin{array}{c}\text { Upper Middle } \\
\text { Class }\end{array}$ & Middle Class & Working Class & Poor \\
\hline 1 & 2 & 3 & 4 & 5 \\
\hline
\end{tabular}

5. What is the highest level of education you have completed?

\begin{tabular}{|c|c|c|c|c|c|c|c|}
\hline $\begin{array}{c}\text { No } \\
\text { formal } \\
\text { education }\end{array}$ & $\begin{array}{c}\text { Elementary } \\
\text { school }\end{array}$ & $\begin{array}{c}\text { Some } \\
\text { High } \\
\text { School }\end{array}$ & $\begin{array}{c}\text { Completed } \\
\text { High } \\
\text { School }\end{array}$ & $\begin{array}{c}\text { Some } \\
\text { College / } \\
\text { University }\end{array}$ & $\begin{array}{c}\text { College } \\
\text { Diploma / } \\
\text { Undergraduate } \\
\text { Degree }\end{array}$ & $\begin{array}{c}\text { Some } \\
\text { Graduate / } \\
\text { Professional } \\
\text { School }\end{array}$ & $\begin{array}{c}\text { Hold } \\
\text { Graduate / } \\
\text { Professional } \\
\text { Degree }\end{array}$ \\
\hline 1 & 2 & 3 & 4 & 5 & 6 & 7 & 8 \\
\hline
\end{tabular}

6. What is your religious affiliation?

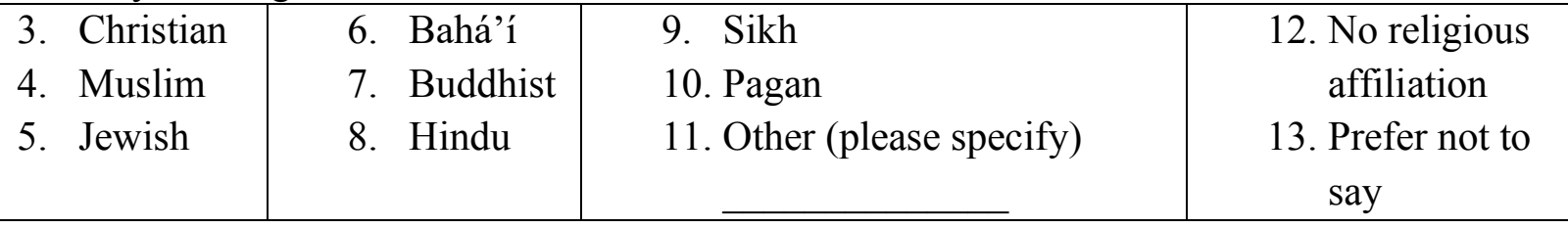

7. How religious do you consider yourself to be?

\begin{tabular}{|c|c|c|c|c|c|c|}
\hline Not at all & $\begin{array}{c}\text { Not } \\
\text { religious }\end{array}$ & $\begin{array}{c}\text { More } \\
\text { secular } \\
\text { than } \\
\text { religious }\end{array}$ & Neutral & $\begin{array}{c}\text { More } \\
\text { religious } \\
\text { than secular }\end{array}$ & Religious & $\begin{array}{c}\text { Very } \\
\text { religious }\end{array}$ \\
\hline 1 & 2 & 3 & 4 & 5 & 6 & 7 \\
\hline
\end{tabular}

8. How would you describe your political orientation on most issues?

\begin{tabular}{|c|c|c|c|c|c|c|}
\hline $\begin{array}{c}\text { Strongly } \\
\text { Left }\end{array}$ & Left & $\begin{array}{c}\text { Somewhat } \\
\text { left }\end{array}$ & Centre & $\begin{array}{c}\text { Somewhat } \\
\text { right }\end{array}$ & Right & $\begin{array}{c}\text { Strongly } \\
\text { right }\end{array}$ \\
\hline 1 & 2 & 3 & 4 & 5 & 6 & 7 \\
\hline
\end{tabular}

9. Are you currently a student? If "yes", what program are you in?

14. Yes (1)

15. No (2) 


\section{Experiment 1b-Materials}

\section{Collective Autonomy Support vs. Restriction Manipulation}

\section{Collective Autonomy Support Condition:}

Collective autonomy refers to whether you feel that your group - in this case your $L G B T Q+$ community -is free to define and express who you are as a people (e.g., your values and beliefs, your ways of behaving).

You may perceive a strong sense of collective autonomy when you feel that other groups in society support your group's freedom to express your own customs and values and to act in ways that reflect who you are as a people.

Please think about your own experiences as part of the LGBTQ+ community. We want to know about a time you can recall when you felt that your community's collective autonomy was supported.

For example: There may have been a specific time or event that made you feel that the $L G B T Q+$ community had the support of groups from outside the community (e.g., marriage equality laws passed in the U.S., more awareness and exposure for trans people in the media - tv shows, tours, etc.,).

\section{Collective Autonomy Restriction Condition:}

Collective autonomy refers to whether you feel that your group - in this case your $L G B T Q+$ community -is free to define and express who you are as a people (e.g., your values and beliefs, your ways of behaving). You may perceive a lack of collective autonomy when you feel that other groups in society try to control how your group expresses your own customs and values and restricts your group from acting in ways that reflect who you are as a people.

Please think about your own experiences as part of the LGBTQ+ community. We want to know about a time you can recall when you felt that your community's collective autonomy was threatened.

For example: There may have been a specific time or event that made you feel that the $L G B T Q+$ community was being restricted by groups from outside the community (e.g., prohibition of $L G B T Q+$ people and messages in Russia, lack of support for making things more gender neutral - washrooms, children's clothes and toy sections in stores, etc.,). 


\section{Measures Reported in Experiment 1b of Present Manuscript}

\section{Demographics}

1. Please state your age in years? (e.g. 22, 46, et cetera).

Please select your gender.

- She/Her (Feminine)

- $\mathrm{He} / \mathrm{Him} /$ (Masculine)

- They/Them (Neutral)

- Other (please specify)

Do you identify as being part of the LGBTQ+ community? Yes/ NO

Which ethnic group do you belong to?

- Black / African American

- Asian / Asian American / Pacific Islander

- White / European American

- Latino / Hispanic American

- Middle Eastern / Arab American

- Native American

- Biracial / Mixed Race (please specify)

- Other (please specify)

Do you consider the U.S. to be your native country?

- Yes

- No 


\section{Subgroup Identification (Items developed by authors):}

Which group(s) within the LGBTQ+ community do you feel most strongly connected to? Please choose all groups that apply.

- The Trans community (e.g., those connecting based on their marginalized gender identities - people who may identify as transgender, transsexual, non-binary, genderqueer, etc.)

- The Gay and Lesbian community (e.g., those connecting based on their marginalized sexual orientations - people who may identify as gay, lesbian, bisexual, asexual, pansexual, etc.)

The LGBTQ+ community as a whole (e.g., those connecting based on the myriad diverse identities represented by the overall community)

Another group or community based on gender and sexual identity not described above (please specify):

I I identify as either non-heterosexual and/or non-cisgender, but do not connect as much with any "community" based on gender and/or sexual identity

\section{Group Identification (Cameron, 2004):}

We would like you to answer some questions about how identified you feel (i.e., how connected you feel) to your LGBTQ+ community as a whole. Please use the scale to indicate the extent to which you agree with each of these statements.

1. I feel strong ties to other LGBTQ+ community members.

2. I don't feel a sense of being "connected" with other members of the LGBTQ+ community.

3. Overall, being LGBTQ+ has very little to do with how I feel about myself.

4. In general, being LGBTQ+ is an important part of my self-image.

5. In general, I am glad to be LGBTQ+.

6. I don't feel good about being LGBTQ+. 
Personal Autonomy Need Satisfaction (Sheldon \& Gunz, 2009):

Please rate the following items thinking about how you felt during the TIME/EVENT YOU DESCRIBED IN THE WRITING TASK.

1. There were people telling me what I had to do.

2. I was free to do things in my own way.

3. I had a lot of pressures I could do without.

4. My choices expressed my "true self"

5. I had to do things against my will.

6. I was really doing what interests me.

Psychological Well-Being (Legate et al., 2017)

Please rate the following items thinking about how you felt during the TIME/EVENT YOU DESCRIBED IN THE WRITING TASK.

1. In most ways my life was close to ideal.

2. The conditions of my life were excellent.

3. I felt satisfied with my life.

4. I felt sad.

5. I felt lonely.

6. I felt depressed.

7. I felt mad or irritated.

8. I felt angry.

9. I felt hostile.

10. I felt satisfied with myself.

11. I felt useless.

12. I had a positive attitude about myself.

13. I felt panicky.

14. I felt edgy or anxious.

15. I felt nervous and uptight. 


\section{Openness about Sexual and/or Gender Identity (Legate et al., 2017)}

Please rate the following items about how you felt during the TIME/EVENT YOU

DESCRIBED IN THE WRITING TASK. If certain contexts do not apply for you during the time/event, please leave those responses blank (e.g., if you were not in contact with your parents at the time, or were not in school, etc.,).

1. I felt open and comfortable about my sexual and/or gender identity around my parents.

2. I felt open and comfortable about my sexual and/or gender identity around my friends.

3. I felt open and comfortable about my sexual and/or gender identity around my peers at school.

4. I felt open and comfortable about my sexual and/or gender identity around my colleagues at work.

\section{Collective Autonomy Restriction (Adapted from Kachanoff et al., 2018)}

Please rate the following items thinking about how you felt during the TIME/EVENT YOU DESCRIBED IN THE WRITING TASK.

1. My LGBTQ+ community felt free to determine who we are as a people (reversed scored).

2. My LGBTQ+ community did NOT always feel free to determine our own group identity: our customs, practices, values, beliefs, traditions.

3. My LGBTQ+ community felt free to behave in ways that reflected our community's values and shared beliefs openly in society (reversed scored).

4. My LGBTQ+ community did NOT feel free to express our identities and practice our customs openly in society.

5. Other groups tried to prevent my LGBTQ+ community from practicing our own customs openly in society

6. Other groups tried to control what my LGBTQ+ community should value and believe.

7. Other groups did NOT try to prevent my LGBTQ+ community from expressing our identities and practicing our customs openly in society (reversed scored).

8. Other groups did NOT try to prevent my LGBTQ+ community from behaving in ways that reflect our community's values and shared beliefs (reversed scored). 
Personal Autonomy Support in Important Social Contexts (Legate et al., 2017)

Please rate the following items about how you felt during the TIME/EVENT YOU DESCRIBED IN THE WRITING TASK. If certain contexts do not apply for you during the time/event, please leave those responses blank (e.g., if you were not in contact with your parents at the time, or were not in school, etc.,).

1. I felt that my parents provided me with choices and options during our interactions.

2. I felt that my parents understood me.

3. I felt that my parents accepted me as a person.

4. I felt that my friends provided me with choices and options during our interactions.

5. I felt that my friends understood me.

6. I felt that my friends accepted me as a person.

7. I felt that my peers at school provided me with choices and options during our interactions.

8. I felt that my peers at school understood me.

9. I felt that my peers at school accepted me as a person.

10. I felt that my coworkers provided me with choices and options during our interactions.

11. I felt that my coworkers understood me.

12. I felt that my coworkers accepted me as a person.

\section{Additional Measures from Experiment 1b Beyond the Scope of the Present Manuscript}

\section{Open Ended Identification of Gender/Sexual Identity (Item developed by author)}

People describe their sexual and gender identity in different ways. For example, some people describe themselves as a cisgender lesbian woman, a queer trans man, or a trans woman. How do you describe your sexual and gender identity? Please write in the box below. 
Please respond to the statement using the scale, $\mathbf{0}=$ Strong Democrat; $100=$ Strong Republican:

How would you describe your political party preference?

Please respond to the statement using the scale, $0=$ Very liberal; $100=$ Very conservative.

- In terms of economic issues, how would you describe your political attitudes and beliefs?

- In terms of social issues, how would you describe your political attitudes and beliefs?

\section{Are you: (check all that apply)}

I In full-time employment

口 In part-time employment

$\square$ In full-time education

口 In part-time education

$\square$ None of the above

\section{Estimated household income (after tax):}

- Under $\$ 5,000$

- $\$ 5,000-\$ 9,999$

- $\$ 10,000-\$ 14,999$

- $\$ 15,000-\$ 19,999$

- $\$ 20,000-\$ 24,999$

- $\$ 25,000-\$ 34,999$

- $\$ 35,000-\$ 49,999$

- $\$ 50,000-\$ 74,999$

- $\$ 75,000$ - $\$ 99,999$

- $\$ 100,000-\$ 200,000$

- $\$ 200,000-\$ 300,000$

- $\$ 300,000-\$ 500,000$

- $\$ 500,000-\$ 1,000,000$

- Over $\$ 1,000,000$ 
How would you describe your family's social class position?

- Poor

- Working Class

- Middle Class

- Upper Middle Class

- Upper Class

In which region of the United States is your primary residence?

- Northeast

- Midwest

- South

- West

Please indicate the highest level of education you and your parents have completed.

- No Formal Education

- Less than 9th grade

- 9 th to 12 th grade (no diploma)

- Completed High School

- Some College

- BA/BS Degree

- Some Graduate/Professional School

- Hold Graduation/Professional Degree 


\section{Relevance of Writing Task (Items developed by authors)}

1) How much you do you think the event/time you described in the writing task impacts the specific sub-group(s) within the broader LGBTQ+ community that you identify most strongly with.

$1=$ Not at all; $7=$ Very Much

2) In thinking about what you described in the written reflection task, which of the following statements below do you think is most accurate. You can only pick ONE option.

A. Overall, what I wrote about is equally relevant to all the different sub-groups of the LGBTQ + community and the community as a whole.

B. Overall, what I wrote about is most relevant to one specific sub-set of the LGBTQ+ community that I PERSONALLY identify with.

C. Overall, what I wrote about is most relevant to one specific sub-set of the LGBTQ+ community that I personally DO NOT identify with. 


\section{Experiment 2 -Materials}

\section{Collective Autonomy Support vs. Restriction Manipulation}

\section{Collective Autonomy Restriction Condition}

Collective autonomy refers to whether you feel that your group - in this case your LGBTQ+ community -is free to define and express who you are as a people (e.g., your values and beliefs, your ways of behaving). You may perceive a lack of collective autonomy when you feel that other groups in society try to control how your group expresses your own customs and values and restricts your group from acting in ways that reflect who you are as a people.

Please think about your own experiences as part of the LGBTQ+ community. We want you to describe in the text box below a way in which you feel that your community's collective autonomy is threatened.

For example, this can involve your LGBTQ+ community being restricted by groups from outside the community (e.g., push-back against Gay marriage in the U.S., lack of support for making things more gender neutral - washrooms, children's clothes and toy sections in stores, etc.). Please note that you will only be able to proceed after at least two minutes have gone by.

\section{Collective Autonomy Support Condition}

Collective autonomy refers to whether you feel that your group - in this case your LGBTQ+ community -is free to define and express who you are as a people (e.g., your values and beliefs, your ways of behaving).

You may perceive a strong sense of collective autonomy when you feel that other groups in society support your group's freedom to express your own customs and values and to act in ways that reflect who you are as a people.

Please think about your own experiences as part of the LGBTQ+ community. We want you to describe in the text box below a way in which you feel that your community's collective autonomy is supported.

For example, this can involve your LGBTQ+ community having the support of groups from outside the community (e.g., marriage equality laws passed in the U.S., more awareness and exposure for trans people in the media - tv shows, tours, etc.,).

Please note that you will only be able to proceed after at least two minutes have gone by. 


\section{Demographics}

Age Please state your age in years? (e.g., 22, 46, et cetera).

LGBTQ+ Cat Do you identify as part of the LGBTQ+ community or as a non-heterosexual or a non-cisgender individual?
1. Yes
2. No

Gender Please select the pronouns you most identify with:

She/Her (Feminine)

$\mathrm{He} / \mathrm{Him} /$ (Masculine)

They/Them (Neutral)

Other (please specify)

Were you born in the United States?

Yes

No

Ethnicity Which ethnic group do you belong to?

African American/Black

Asian/Asian American/Pacific Islander

Caucasian/White

Latino/Hispanic

Middle Eastern

Native American

Biracial/Mixed race (please specify)

Other (please specify) 


\section{Sub-group identification amongst the LGBTQ+ community (Items developed by authors)}

Which group(s) within the LGBTQ+ community do you feel most strongly connected to? Please choose all groups that apply.

The Trans community (e.g., those connecting based on their marginalized gender identities - people who may identify as transgender, transsexual, non-binary, genderqueer, etc.,)

- The Gay and Lesbian community (e.g., those connecting based on their marginalized sexual orientations - people who may identify as gay, lesbian, bisexual, asexual, pansexual, etc.,)

The LGBTQ+ community as a whole (e.g., those connecting based on the myriad diverse identities represented by the overall community)

Another group or community based on gender and sexual identity not described above (please specify):

I identify as either non-heterosexual and/or non-cisgender, but do not connect as much with any "community" based on gender and/or sexual identity

\section{Group Identification}

We would like you to answer some questions about how identified you feel (i.e., how connected you feel) to your LGBTQ+ community as a whole. Please use the scale to indicate the extent to which you agree with each of these statements.

1. I feel strong ties to other LGBTQ+ community members.

2. I don't feel a sense of being "connected" with other members of the LGBTQ+ community.

3. Overall, being LGBTQ+ has very little to do with how I feel about myself.

4. In general, being LGBTQ+ is an important part of my self-image.

5. In general, I am glad to be LGBTQ+.

6. I don't feel good about being LGBTQ+.

7. Generally, I feel good when I think about myself as LGBTQ+.

8. I often think about the fact that I am LGBTQ+.

9. I have a lot in common with other LGBTQ+ community members. 


\section{Personal Autonomous Need Satisfaction}

Please respond to the following questions in light of how you feel presently when thinking about the current situation experienced by your LGBTQ+ community that you just described in the writing task.

1. There are people telling me what I have to do.

2. I am free to do things in my own way.

3. I have a lot of pressures I could do without.

4. My choices express my "true self"

5. I have to do things against my will.

6. I am really doing what interests me.

\section{Psychological Well-Being}

Please respond to the following questions in light of how you feel presently when thinking about the current situation experienced by your LGBTQ+ community that you just described in the writing task.

1. In most ways my life is close to ideal.

2. The conditions of my life are excellent.

3. I feel satisfied with my life.

4. I feel sad.

5. I feel lonely.

6. I feel depressed.

7. I feel mad or irritated.

8. I feel angry.

9. I feel hostile.

10. I feel satisfied with myself.

11. I feel useless.

12. I have a positive attitude about myself.

13. I feel scared or panicky.

14. I feel edgy or anxious.

15. I feel nervous and uptight. 


\section{Openness About Sexuality and/or Gender Identity within Interpersonal Contexts}

Please respond to the following questions in light of how you feel presently when thinking about the current situation experienced by your LGBTQ+ community that you just described in the writing task. If certain contexts do not apply for you now, please leave those responses blank (e.g., if you are not in contact with your parents at this time, or you are not in school, ect.,).

1. I feel open and comfortable about my sexual and/or gender identity around my parents.

2. I feel open and comfortable about my sexual and/or gender identity around my friends.

3. I feel open and comfortable about my sexual and/or gender identity around my peers at school.

4. I feel open and comfortable about my sexual and/or gender identity around my colleagues at work.

\section{Personal Autonomy Support within Interpersonal Contexts}

Please respond to the following questions in light of how you feel presently when thinking about the current situation experienced by your LGBTQ+ community that you just described in the writing task. If certain contexts do not apply for you now, please leave those responses blank (e.g., if you are not in contact with your parents at this time, or you are not in school, ect.,).

1. I feel that my parents provide me with choices and options during our interactions.

2. I feel that my parents understand me.

3. I feel that my parents accept me as a person.

4. I feel that my friends provide me with choices and options during our interactions.

5. I feel that my friends understand me.

6. I feel that my friends accept me as a person.

7. I feel that my peers at school provide me with choices and options during our interactions.

8. I feel that my peers at school understand me.

9. I felt that my peers at school accept me as a person.

10. I felt that my coworkers provide me with choices and options during our interactions.

11. I feel that my coworkers understand me.

12. I feel that my coworkers accept me as a person. 


\section{Collective Autonomy Restriction}

Please respond to the following questions in light of how you feel presently when thinking about the current situation experienced by your LGBTQ+ community that you just described in the writing task.

1. My LGBTQ+ community feels free to determine who we are as a people.

2. My LGBTQ+ community does NOT always feel free to determine our own group identity: our customs, practices, values, beliefs, traditions.

3. My LGBTQ+ community feels free to behave in ways that reflect our community's values and shared beliefs openly in society.

4. My LGBTQ+ community does NOT feel free to express our identities and practice our customs openly in society.

5. Other groups try to prevent my LGBTQ + community from practicing our own customs openly in society.

6. Other groups try to control what my LGBTQ+ community should value and believe.

7. Other groups do NOT try to prevent my LGBTQ+ community from expressing our identities and practicing our customs openly in society.

8. Other groups do NOT try to prevent my LGBTQ+ community from behaving in ways that reflect our community's values and shared beliefs.

\section{Anti-LGBTQ+ Discrimination}

Please respond to the following questions in light of how you feel presently when thinking about the current situation experienced by your LGBTQ+ community that you just described in the writing task.

1. It is common that other groups discriminate against members of my LGBTQ+ community.

2. My LGBTQ+ community is the target of prejudice.

3. It is rare that members of my LGBTQ+ community face discrimination.

4. If you are reading this question carefully, please select three. 
Additional Measures from Experiment 2 Beyond the Scope of the Present Manuscript Other demographics collected

Income Please indicate your YEARLY household income, before taxes.

$$
\begin{aligned}
& \text { Under } \$ 5,000 \\
& \$ 5,000-\$ 9,999 \\
& \$ 10,000-\$ 14,999 \\
& \$ 15,000-\$ 19,999 \\
& \$ 20,000-\$ 24,999 \\
& \$ 25,000-\$ 34,999 \\
& \$ 35,000-\$ 49,999 \\
& \$ 50,000-\$ 74,999 \\
& \$ 75,000-\$ 99,999 \\
& \$ 100,000-\$ 200,000 \\
& \$ 200,000-\$ 300,000 \\
& \$ 300,000-\$ 500,000 \\
& \$ 500,000-\$ 1,000,000 \\
& \text { Over } \$ 1,000,000
\end{aligned}
$$

In which region of the United States is your primary residence?

Northeast

Midwest

South

West 
What is the highest level of education you have completed?

No Formal Education

Less than 9th grade

9th to 12 th grade (no diploma)

Completed High School

Some College

BA/BS Degree

Some Graduate/Professional School

Hold Graduation/Professional Degree

People describe their sexual and gender identity in different ways. For example, some people describe themselves as a cisgender lesbian woman, a queer trans man, or a trans woman. How do you describe your sexual and gender identity? Please write in the box below.

\section{Relevance of Writing Task (Items developed by authors)}

In thinking about what you described in the writing task, which of the following statements below do you think is most accurate. You can only pick ONE option.

1. Overall, what I wrote about is equally relevant to all the different sub-groups of the LGBTQ+ community and the community as a whole.

2. Overall, what I wrote about is most relevant to one specific sub-set of the LGBTQ+ community that I PERSONALLY identify with.

3. Overall, what I wrote about is most relevant to one specific sub-set of the LGBTQ+ community that I personally DO NOT identify with. 


\section{References for Supplemental Materials}

Cameron, J. E. (2004). A three-factor model of social identity. Self and Identity, 3, 239-262. DOI: $10.1080 / 13576500444000047$

Chirkov, V., Ryan, R. M., Kim, Y., \& Kaplan, U. (2003). Differentiating autonomy from individualism and independence: A self-determination theory perspective on internalization of cultural orientations and well-being. Journal of Personality and Social Psychology, 84, 97-110. DOI: 10.1037/0022-3514.84.1.97

Crocker, J., \& Luhtanen, R. (1990). Collective self-esteem and ingroup bias. Journal of Personality and Social Psychology, 58, 60. doi:10.1037/0022-3514.58.1.60

Diener, E., Emmons, R. A., Larsen, R. J., \& Griffin, S. (1985). The satisfaction with life scale. Journal of Personality Assessment, 49, 71-75. DOI:10.1207/s15327752jpa4901_13

Haddock, G., Zanna, M. P., \& Esses, V. M. (1993). Assessing the structure of prejudicial attitudes: The case of attitudes toward homosexuals. Journal of Personality and Social Psychology, 65, 1105. DOI:10.1037/0022-3514.65.1105

Hogg, M. A., Sherman, D. K., Dierselhuis, J., Maitner, A. T., \& Moffitt, G. (2007). Uncertainty, entitativity, and group identification. Journal of Experimental Social Psychology, 43, 1 35-142. DOI: 10.1016/j.jesp.2005.12.008

Kachanoff, F. J., Taylor, D. M., Caouette, J., Khullar, T. H., \& Wohl, M. J. A. (2018). The chains on all my people are the chains on me: Restrictions to collective autonomy undermine the personal autonomy and psychological well-being of group members. Journal of Personality and Social Psychology. DOI: 10.1037/pspp0000177 
Legate, N., Ryan, R. M., \& Rogge, R. D. (2017). Daily autonomy support and sexual identity disclosure predicts daily mental and physical health outcomes. Personality and Social Psychology Bulletin, 43, 860-873. DOI: 10.1177/0146167217700399

Sheldon, K. M., \& Gunz, A. (2009). Psychological needs as basic motives, not just experiential requirements. Journal of Personality, 77, 1467-1492. DOI: 10.1111/j.14676494.2009.00589.x

Shnabel, N., \& Nadler, A. (2008). A needs-based model of reconciliation: Satisfying the differential emotional needs of victim and perpetrator as a key to promoting reconciliation. Journal of Personality and Social Psychology, 94, 116-132. DOI: 10.1037/0022-3514.94.1.116

Weinstein, N., Ryan, W. S., DeHaan, C. R., Przybylski, A. K., Legate, N., \& Ryan, R. M (2012). Parental autonomy support and discrepancies between implicit and explicit sexual identities: Dynamics of self-acceptance and defense. Journal of Personality and Social Psychology, 102, 815. DOI: 10.1037/a0026854

Wohl, M. J., Branscombe, N. R., \& Reysen, S. (2010). Perceiving your group's future to be in jeopardy: Extinction threat induces collective angst and the desire to strengthen the ingroup. Personality and Social Psychology Bulletin, 36, 898-910. DOI:

$10.1177 / 0146167210372505$ 